\title{
Evaluation of Mechanical Properties of Polysaccharide Films Prepared from Furcellaria Lumbricalis and Gigartina Skottsbergii Seaweeds by PF-QNM Technique
}

\section{Ivan Simkovic ( $\square$ chemsimk@savba.sk)}

Slovak Academy of Sciences https://orcid.org/0000-0003-4107-1529

\section{Filip Gucmann}

Electrotechnical Instituete, SAS, Slovakia

\section{Raniero Mendichi}

Analysis, Molecular and Rheological Characterization of complex polymersr

Alberto Giacometti Schieroni

CNR "G. Natta, Milan

Daniele Piovani

CNR "G. Natta", Milan

\section{Edmund Dobročka}

SAS

\section{Miloš Hricovíni}

Institute of Chemistry, SAS, Bratislava

\section{Research Article}

Keywords: Red algae seaweeds, NMR, SEC-MALS, films properties, XRD, PF-QNM

Posted Date: June 3rd, 2021

DOI: https://doi.org/10.21203/rs.3.rs-562088/v1

License: (9) (i) This work is licensed under a Creative Commons Attribution 4.0 International License. Read Full License 


\section{Abstract}

Films from Furcellaria lumbricalis (FL) and Gigartina skottsbergii (GS) seaweed extracts were prepared and their properties were investigated. According to NMR analysis of GS ultrasonic water (GSUW) extraction (1-3)-a-glycan 6-sulfate was isolated. The analogical treatment with carbonate-peroxide solution (GSUCP) resulted in a mixture of the same glycan and carrageenan hybrids $\mu$-D6S and v-D2S,6S observed for the first time in this study. The extraction of GS in boiling water under reflux (GSW) in comparison to FL (FLW), indicates that GSW consisted of the most complex mixture of $a-, \beta-, K-,-, \theta-, \zeta-$ carrageenans, (1-3)-a-glycan partially sulfated at $C_{6}$, and $\mu-D 6 S$ and v-D2S,6S hybrids. The analogical FLW extract contained $a-, \theta-, \lambda-, \mu$-, $v$ - and $\zeta$-carrageenans and (1-3)-a-glycan partially sulphated at $C_{6}$. SEC-MALS results indicate that molecular weight of chromatographic main peak $\left(M_{p}\right)$ is decreasing: GSUCP $(994 \mathrm{~kg} / \mathrm{mol})>\operatorname{GSUW}(565 \mathrm{~kg} / \mathrm{mol})>$ FLW $(498 \mathrm{~kg} / \mathrm{mol})>$ l-carrageenan $(264 \mathrm{~kg} / \mathrm{mol})>\mathrm{k}-$ carrageenan $(174 \mathrm{~kg} / \mathrm{mol})>$ furcellaran $(144 \mathrm{~kg} / \mathrm{mol})>\mathrm{GSW}(78 \mathrm{~kg} / \mathrm{mol})$. Macromolecules conformation is varying from flexible random coil for $\mathrm{K}$-carrageenan to nearly compact spheres for t-carrageenan. Furcellaran conformation is intermediate between $\mathrm{k}$-carrageenan and t-carrageenan, specifically a little more compact than K-carrageenan. XRD analysis confirmed no cellulose content in all prepared films. AFM and PF-QNM analysis showed relations between values of $R_{g}$ and $M_{p}$ and the values of surface roughness, reduced moduli, stiffness and adhesion.

\section{Introduction}

Red algae polysaccharides, in particular films prepared from water extracts of these polysaccharides represent a source of materials with unexplored properties (Jamróz at al. 2020; Šimkovic 2013; Usov 2011). To identify a relation between polysaccharide structure and corresponding film properties, several polysaccharide fractions were isolated and studied in detail. Owing to its simplest structure, our study begins with analysis of furcellaran isolated from Furcellaria lumbricalis (Knutsen and Grasdalen, 1987). According to recent review on furcellaran, it is considered a complex polysaccharide, containing both $\beta$ and $\mathrm{k}$-carrageenan structural elements in one chain (Marangoni et al. 2021). The carrageenans consist of alternating $\beta$ - $(1 \rightarrow 4)$-D- and $\mathrm{a}-(1 \rightarrow 3)$-D-galactose $(G)$ or 3,6-anhydro-D-galactose (DA) dimer repeating units. The furcellaran films characterization was undertaken to analyse their physical, mechanical and structural properties (Jamróz at al. 2020). While $\beta$-carrageenan does not contain sulphate groups and consists of ${ }^{4} C_{1}$ chair $\beta$-( $(1 \rightarrow 4)$-D-galactose unit $(G)$ and ${ }^{1} C_{4}$ 3,6-anhydro-D-galactose (DA) dimer repeating units, K-carrageenan has one sulphate on G unit linked to C-4 (G4S). The t-carrageenan consists of G4S and DA2S repeating units with sulfate groups on both units (Préchoux et al. 2014). According to the revised carrageenan ${ }^{13} \mathrm{C}$-NMR data, eight carrageenans were assigned indicating similar chemical shifts (van de Velde et al. 2004). There are previously reported attempts to characterize the carrageenan mixtures by nuclear magnetic resonance (NMR), however to our best knowledge, there are no NMR data on pure $\gamma$ - or $\pi$ - and many other carrageenans (Dyrby et al. 2004). Seven different carrageenans were identified in Gigartina skottsbergii (GS) by ${ }^{13} \mathrm{C}-\mathrm{NMR}$ and methylation analysis (Ciancia et al. 1993). Independent data identified the $\lambda$-carrageenan, indicating its presence in GS (Guibert et al. 2006; Ficko et 
al. 2017). GS and other seaweeds are known as red algae containing carrageenans with antiviral activity (Pujol et al. 2006; Kwon at al. 2020). These polysaccharides could be used in medicine and are suitable for preparation of films (Sedayu et al. 2019). In addition, antioxidant properties of K-carrageenan and other seaweed polysaccharides were reported (Marangoni et al. 2021; Sun et al. 2010; He at al. 2016; Mirzadeh at al. 2020). GS and FL are suitable species for comparative study of film properties prepared from water extracts (Šimkovic 2013). A complete water solubility of polysaccharide components and prevention of non-polysaccharide components in the prepared film is required for high quality film preparation. Increased amount of sulfate groups leads to a decreased effects of intra- and intramolecular hydrogen bond interactions in film consisting of polysaccharide blends and cause the loss of required properties. To guarantee the film purity, more detailed two-dimensional NMR studies are needed to identify the components of carrageenan mixtures and possible new structures.

Films prepared from seaweed extracts have also potential applications as heparin analogues due to their sulphate groups (Kwon et al. 2020). However, the available amount of information on the relationship between their structure and mechanical properties is currently insufficient (Truus et al., 1997). While k-and $\mathrm{t}$-carrageenans are known for forming helixes and gels in water, the sequence motif of $\lambda$-carrageenan has been suggested to prevent the formation of secondary structure and thus gel formation.

These are materials with environmentally harmless properties, with applications in packaging, food processing, medicine, electrical engineering and other fields, many of which cannot be predicted in the present days due to ongoing basic research on their various material properties. It was shown, that films prepared from $\lambda-,-$, , and $\mathrm{k}$-carrageenan on mica have random coil end-to-end or helical distances at different concentrations and various ion strengths ranging from 75 to $250 \mathrm{~nm}$ (Schefer et al. 2015). Additionally, seaweeds contain certain amount of cellulose, which always affects the mechanical properties of the films due to its dilution to water extracts resulting in water suspension. For this reason, X-ray diffraction (XRD) analysis of films prepared from seaweed or other extracts are needed to obtain a full picture on film properties and their potential usage (Paniz at al. 2020; Šimkovic at al. 2014; 2013).

For use in packaging technology, mechanical properties of polysaccharide films are some of the most important. Mechanical properties can be determined by various methods e.g. using standard mechanical testing or nanoindentation, both especially beneficial in evaluation of bulk material properties. However, to obtain nanoscale spatially-resolved mechanical properties, atomic force microscopy (AFM)-based mechanical testing becomes useful, as previously successfully demonstrated in numerous studies. Mapping of mechanical properties is an example of one category of current AFM-based techniques and counts several distinctive methods such as contact resonance mapping, force-volume mapping (FVM), and peakforce quantitative nanomechanical mapping (PF-QNM), which was used in this study to determine the mechanical properties of prepared seaweed films.

Similarly to nanoindentation and FVM, PF-QNM acquires force-displacement curves (force curves), which are subsequently analyzed and appropriate analytical model is applied to extract desired mechanical properties. Nanoindentation uses typically a sharp diamond tip of chosen geometry to indent the studied 
sample; corresponding indentation depth can be selected to study surface or bulk material properties. In contrast, FVM and PF-QNM techniques use appropriate AFM probe - a sharp tip (typ. Si or diamond) on flexible $\mathrm{Si}$ or $\mathrm{Si}_{3} \mathrm{~N}_{4}$ cantilever. Both techniques are similar, however much faster data acquisition rates and applied force control favors PF-QNM. Spring constant $(K)$ of the flexible cantilever needs to be matched with the elastic modulus of the material studied, i.e. sample indentation depth must be comparable to cantilever deflection. As a result, and as opposed to nanoindentation, AFM-based nanomechanical mapping techniques are usually suitable for studies of materials with elastic modulus below and up to 100GPa. Typical indentation depths in AFM-based nanomechanical mapping techniques are 5-10 nm, or can be in the order of several 10 s of $n m$ in case of very soft samples such as living cells or bacteria. This means mechanical properties provided by these techniques are strictly related to the surface, rather than to the bulk of the studied materials. Details of these techniques can be found elsewhere (Gavara, 2017, Kaemmer 2011, Pittenger, et al., 2013). AFM-based nanomechanical mapping was recently used e.g. to study mechanical properties of biomolecule films (Kurland et al. 2012). PF-QNM was also successfully applied in detailed mapping of mechanical properties of single nanocellulose fibrils (Usov, et al., 2015).

The main goal of this study is to find a new relation between seaweed polysaccharide structure and various material properties of the prepared films. With the help of NMR, and size-exclusion

chromatographic multi-angle laser light scattering (SEC-MALS) analysis, we characterized the structure of furcellaran, $\mathrm{k}$ - and t-carrageenan, GS water extract (GSW), GS ultrasound water azide extract (GSUW), and GS ultrasound water carbonate-peroxide extract (GSUCP). These films were subsequently characterized by thermogravimetry (TG/DTG/DTA), XRD, and PF-QNM to evaluate their behavior at elevated temperatures, cellulose content, and their mechanical properties, respectively. Our results demonstrate prepared polysaccharide films exhibited suitable properties required for medical and other eco-friendly applications.

\section{Materials And Methods}

\section{Materials}

Furcellaran (C, 28.65; H, 4.39; N, 0.00; S, 2.25; AP 148; Knutsen and Grasdalen 1987) and Furcellaria lumbricalis (FL; C, 31.50; H, 5.19; N, 2.90; S, 3.69) were donated from Dr. S. H. Knutsen. Samples of tcarrageenan (C, 23.06; H, 4.24; N, 0.00; S, 6.44); K-carrageenan (C, 27.96; H, 4.54; N, 0.00; S, 3.16), Gigartina skottsbergii (GS; C, 23.92; H, 4.75; N, 1.36; S, 9.47) were supplied by CP Kelco, Denmark. All other chemicals were obtained from commercial sources and used without further purification.

\section{Water extraction of GS}

GS seaweed meal ( $5 \mathrm{~g}$; particle size $<2 \mathrm{~mm}$ ) was mixed with deionized water $(200 \mathrm{ml})$ and treated under reflux in an Erlenmeyer flask using oil bath at $100^{\circ} \mathrm{C}$ for 24 hours. The mixture was dialyzed $(3.5 \mathrm{kDa}$ MWCO, Union Carbide, USA) and separated to water extract (GSW) and insoluble residue (GSIR) by 
centrifuge ( $60 \mathrm{~min} / 13,900 \mathrm{RPM})$. Both parts were lyophilized and characterized by elemental analysis (GSW; 68 \% yield; C, 24.13; H, 4.40; N, 0.47; S, 9.37; GSIR; 20 \% yield; C, 45.13; H, 6.10; N, 7.46; S, 1.37).

\section{Water extraction of FL}

FL seaweed meal ( $5 \mathrm{~g}$; particle size $<2 \mathrm{~mm}$ ) was treated identically to GS. The mixture was dialyzed (3.5 kDa MWCO, Union Carbide, USA) and separated to water extract (FLW) and insoluble residue (FLIR) by centrifuge ( $60 \mathrm{~min} / 13,900 \mathrm{RPM})$. Both parts were lyophilized and characterized by elemental analysis (FLW, 44\% yield; C, 21.79; H, 3.99; N, 0.37; S, 11.80); FLIR, 8\% yield; C, 41.03; H, 5.90; N, 7.90; S, 2.99).

\section{Ultrasonic water extraction of GS}

GS seaweed meal ( $5 \mathrm{~g}$; particle size $<2 \mathrm{~mm}$ ) was sonicated in a SONOPULS ultrasonic homogenizer (BANDELIN, Germany) at $75 \mathrm{~W}$ power and ultrasound frequency of $20 \mathrm{kHz}$ for 60 minutes using the KE 76 probe (at $212 \mathrm{~kJ}$ of total converted mechanical energy) in a mixture of deionized water $(200 \mathrm{~mL}$ ) containing $\mathrm{NaN}_{3}(0.05 \mathrm{~g})$. The used glassware was cooled in a water bath to maintain room temperature (RT). The water suspension was dialyzed and separated to water extract and insoluble residue by centrifuge similarly to GS and FL case. Both parts were lyophilized and characterized by elemental analysis (GSUW, 42\% yield; C, 22.40; $H, 3.84 ; \mathrm{N}, 0.51$; $S, 11.94$; GSUWIR, 37\% yield; $C, 30.13 ; \mathrm{H}, 4.70$; N, $3.40 ; \mathrm{S}, 8.77)$.

\section{Ultrasonic water carbonate peroxide extraction of GS}

GS seaweed meal ( $5 \mathrm{~g}$; particle size $<2 \mathrm{~mm}$ ) was mixed with hydrogen peroxide/sodium carbonate adduct (ALDRICH; \#371432, available $\mathrm{H}_{2} \mathrm{O}_{2} \sim 20-30 \%$ ) in water $(200 \mathrm{ml}$ ) and homogenized as above (184 kJ of total converted mechanical energy). The sample was prepared in the same way as GSUP; and in this way, the ultrasound water carbonate-peroxide extract (63\% yield, GSUCP; C, 21.65; H, 4.09; N, 0.34; $S, 11.64)$ and the insoluble residue (11 \% yield, GSUCPIR; $C, 40.69 ; \mathrm{H}, 6.12 ; \mathrm{N}, 7.76 ; \mathrm{S}, 3.63)$ were obtained.

\section{Films preparation}

All prepared seaweed extracts $(0.1-0.5 \mathrm{~g})$ were mixed with $50-100 \mathrm{ml}$ of water and solubilized for 2 hours at 1000 RPM, poured in plastic petri dishes (Greiner Bio-One $\mathrm{GmbH}$, Austria; $8.5 \mathrm{~cm}$ in diameter) and allowed to dry at RT up to constant weight of the specimen.

\section{Analytical methods}

The elemental composition was determined using a Macro Analyzer (Elemental Analysen system GmbH, Donauestr, 7, 63452 Hanau, Germany) at the following detection ranges: C: 0-150 mg (or $100 \%$ ); H: 0-15 mg (or $100 \%$ ); N: 0-100 mg (or $100 \%$ ) and S: 0-18 mg (or 100\%).

The NMR experiments were run in $\mathrm{D}_{2} \mathrm{O}$ (99.96\%; euriso-top, France) at $40^{\circ} \mathrm{C}$ using 3-(trimethylsilyl)-2, 2, 3, 3-tetradeuteropropionic acid, TMSP- $d_{4}$ (TSP) as internal standard. The NMR data were analyzed using 
the Mnova software (version 12.0.3). The conditions of ${ }^{1} \mathrm{H}-\mathrm{NMR}, \mathrm{COSY}, \mathrm{TOCSY}, \mathrm{HSQC}$ and HMBC were used as described previously (Šimkovic et al. 2020).

The molecular weight distribution (MWD) and size of the macromolecules (radius of gyration, $R_{g}$ ) were obtained using an absolute multi-angle laser light scattering (MALS) detector connected to a sizeexclusion chromatographic (SEC) system. We used the $0.1 \mathrm{M}$ acetate buffer at $\mathrm{pH} 4.5$ for characterization of all samples using a modular multi-detector Alliance 2695 chromatographic system from Waters (USA). The Alliance SEC system was equipped with a MALS Dawn-DSP detector from Wyatt Technology (USA) and a 2414 differential refractometer (DRI) from Waters (USA) as concentration detector. Following experimental conditions were used: two Shodex aqueous columns -OHPak SB (806HQ-805HQ) from Showa Denko $(\mathrm{J}) ; 35^{\circ} \mathrm{C}$ temperature; $0.8 \mathrm{ml} / \mathrm{min}$ flow rate; $\sim 3.0 \mathrm{mg} / \mathrm{ml}$ sample concentration; refractive index excess of the polymer respect to the solvent $\mathrm{dn} / \mathrm{dc}=0.146 \mathrm{ml} / \mathrm{g}$.

The X-ray diffraction analysis was carried out using Bruker D8 DISCOVER diffractometer equipped with Xray source with rotating $\mathrm{Cu}$ anode operating at $12 \mathrm{~kW}$. All measurements were performed in parallel beam geometry with parabolic Goebel mirror in the primary beam producing the beam divergence of $\sim 0.03^{\circ}$. All XRD patterns were recorded in grazing incidence (GI) setup with constant angle of incidence $a=2^{\circ}$. The advantage of this setup is that the shape and the size of the measured area as well as the penetration depth of X-rays do not change during the measurement. This method is also insensitive to surface roughness and/or other irregularities. All patterns were measured in the angular range of $5^{\circ}-40^{\circ}$ with step size of $0.05^{\circ}$ and integration time of 1 s per step.

Bruker MultiMode 8-HR atomic force microscope using Si Micromasch HQ: NSC15 probes (K 20-40N/m; https://www.spmtips.com/afm-tip-HQ-NSC15-Al-BS) in peakforce tapping mode was used to study surface morphology and nanomechanical properties of all polysaccharide films. Approximately $1 \times 1 \mathrm{~cm}$ piece coupon cut away from each of the 7 studied samples was glued onto separate $12 \mathrm{~mm}$ diameter steel disc sample holders, rear side (the one in previous contact with the petri dish) facing upwards. Topography, spatially resolved mechanical properties (reduced elastic modulus and stiffness), and adhesion was evaluated from several different locations (3-8) across the coupon surface to observe the repeatability of measured data and to decrease the uncertainty of extracted values. To avoid wrinkles or any large surface variations related to mounting of the samples, size of the scans presented here was limited to $2 \times 2 \mu \mathrm{m}$. In samples, where a distinctive grainy surface texture was observed ( $\mathrm{l}$-carrageenan, $\mathrm{K}$ carrageenan, furcellaran), statistical analysis was applied to topography scans to extract correlation length of the observed grains, i.e. gyration radii of coils corresponding to polysaccharide molecule conformations. A discrete one-dimensional (1D) autocorrelation function (ACF) in fast-scan direction was calculated using Gwyddion software (D. Nečas, et al., 2012, http://gwyddion.net/documentation/userguide-en/statistical-analysis.html) assuming:

$$
G(m)=\frac{1}{M-m} \sum_{k=1}^{M-m} z_{k} z_{k+m}
$$


where $G(m)$ is the 1D ACF, $M$ is number of samples, $m=\tau_{X} / \Delta x$ correspond to points distance separated by sampling interval, and $z_{k}$ and $z_{k+m}$ are respective values of heights at points $k$ and $k+m$. Calculated 1D ACF was approximated assuming Gaussian distribution:

$$
G_{x}\left(\tau_{x}\right)=\sigma^{2} \exp \left(-\tau_{x}^{2} / T^{2}\right),
$$

, where $\sigma$ denotes root mean square variations of heights (i.e. root mean square, RMS, roughness) and $T$ is the autocorrelation length.

\section{PF-QNM calibration and force curves analysis}

A comprehensive, three-step calibration was carried out prior to PF-QNM data acquisition: (i) calibration of cantilever deflection sensitivity by obtaining several subsequent force curves by ramping the probe on hard surface sample and taking their average value. SAPPHIRE-12M test sample from Bruker was used. Deflection sensitivity of a) $35.09 \pm 0.2 \mathrm{~nm} / \mathrm{V}$ and b) $36.27 \pm 0.3 \mathrm{~nm} / \mathrm{V}$ was determined and used for mechanical properties evaluation of a) l-carrageenan, k-carrageenan, and furcellaran, and b) FLW, GSW, GSUW, and GSUCP respectively; (ii) calibration of cantilever spring constant by Sader method (J. E. Sader, et al. 2012, https://sadermethod.org) assuming averaged values of cantilever resonance frequency and $Q$ factor determined from cantilever tuning in tapping mode. Cantilever spring constants of a) $34.8 \pm 3.7$ $\mathrm{N} / \mathrm{m}$ and b) $28.1 \pm 3.0 \mathrm{~N} / \mathrm{m}$ were determined and used for mechanical properties evaluation of a) $\mathrm{t}$ carrageenan, k-carrageenan, and furcellaran and b) FLW, GSW, GSUW, and GSUCP respectively; (iii) determination of tip radius by obtaining a topography scan of Ti roughness test sample RS-12M supplied by Bruker and subsequent tip reconstruction using tip qualification function of the Nanoscope Analysis software. This method enables the calculation of effective tip radius as a function of indentation depth, required for PF-QNM.

Measured raw PF-QNM data were then analysed in the Nanoscope Analysis software, where corresponding values of cantilever deflection sensitivity, cantilever spring constant, and tip radius at appropriate average indentation depth were supplied. Johnson, Kendall, Roberts (JKR) theory (K.L. Johnson, et al., 1971) was applied to force curves acquired at each measured pixel of the scan and reduced elastic modulus $\left(E^{*}\right)$, stiffness, and adhesion maps were determined. Due to unknown values of Poisson's ratio $(v)$ of our samples, we present reduced elastic modulus instead of true elastic modulus $(E)$ values. Assuming much higher elastic modulus of the used AFM tip, than that of the sample $\left(E_{s}\right)$, reduced elastic modulus is defined as, where $v_{s}$ is the Poisson's ratio of the sample. Adhesion may be useful in providing additional information of e.g. local chemistry variations and was determined as the force required to detach the AFM tip from the sample surface after each tapping cycle. Constant force set point was set during each measurement to avoid undesired variations in indentation depth induced by the instrument and was specific for each sample in range of $\sim 2-60 \mathrm{nN}$.

To confirm the accuracy of the PF-QNM calibration and data analysis, mechanical properties of Bruker's PS-LDPE-12M PF-QNM test sample were evaluated. This test sample comprised of polystyrene (PS) and 
polyolefin elastomer (PE) particles spin cased on silicon. Determined values of elastic modulus of PS and PE agreed with manufacturer supplied data corroborating used PF-QNM methodology.

\section{Results And Discussion}

\section{NMR characterization}

The purified furcellaran fraction (Knutsen and Grasdalen 1987), analyzed with HSQC experiment (Fig. 1, left; Table S1 in supplementary information) gave only two anomeric signals. It means $\beta-D A$ and $k-D A$ have identical chemical shifts at 5.10/97.10 ppm ( $\left.{ }^{1} \mathrm{~J}_{\mathrm{CH} 1} 165 \mathrm{~Hz}\right)$, and $\beta-\mathrm{G}$ and $\mathrm{k}-\mathrm{G} 4 \mathrm{~S}$ signals are overlapped at 4.64/104.92 ppm ( $\left.{ }^{1} \mathrm{~J}_{\mathrm{CH} 1} 168 \mathrm{~Hz}\right)$. Small differences were observed for two $\mathrm{H}-2$ signals of $\mathrm{K}-$ DA and $\beta$-DA at 4.14 and 4.09/72.47 ppm in COSY and HSQC spectra. Further assignment for both $\beta$-DA and $\mathrm{K}$-DA units was based on TOCSY and HSQC, e.g. $\mathrm{H}_{3} / \mathrm{C}_{3}$ signals were assigned at 4.55/81.67 ppm, as well as $\mathrm{H}_{3} / \mathrm{C}_{3}(3.89 / 82.46 \mathrm{ppm})$ of $\beta-\mathrm{G}$ and $\mathrm{H}_{3} / \mathrm{C}_{3}(4.01 / 82.46 \mathrm{ppm})$ of $\mathrm{K}-\mathrm{G} 4 \mathrm{~S}$. The known data of $\beta$ - and $\mathrm{K}$-carrageenan were in agreement with our data (see Table S1) and helped to assign the values of signals at $\mathrm{H}_{4} / \mathrm{C}_{4}, \mathrm{H}_{5} / \mathrm{C}_{5}$ and $\mathrm{H}_{6} / \mathrm{C}_{6}$ positions (van de Velde et al. 2004).

The three-bond spin-spin interaction across the glycosidic bond between $\mathrm{H}-1$ of $\mathrm{K}-\mathrm{DA}(5.11 \mathrm{ppm})$ and $\mathrm{C}-3$ of k-G4S (80.74 ppm) was clearly detected in HMBC (Fig. 1, right; Table S1). The same type of interactions were detected between $\beta-D A H-1(5.10 \mathrm{ppm})$ and $\mathrm{C}-3(82.51 \mathrm{ppm})$ of $\beta-\mathrm{G}$ and between $\mathrm{H}-4$ of $\mathrm{K}-\mathrm{G} 4 \mathrm{~S}$ (4.63 ppm) and C-1 of $\mathrm{K}-\mathrm{DA}(105.05 \mathrm{ppm})$. Furthermore, the signal (4.63/105.05 ppm) confirms the connectivity of $\beta-D A$ at $\mathrm{H}-4$ with $\mathrm{C}-1$ of $\beta-\mathrm{G}$. The data from these HSQC and HMBC experiments differ up to two ppm to those presented in the recent review. This difference is likely due to different origin of the compound; presented alkali-modified furcellaran published by the authors from Estonia (Marangoni et al. 2021).

Two anomeric signals (5.30/94.41 and 4.67/104.55 ppm) were detected in HSQC spectrum of tcarrageenan (Fig. 2, left). Both signals were assigned to t-DA2S (5.30/94.41) and to t-G4S (4.67/104.55 ppm) based on ${ }^{13} \mathrm{C}$-NMR data (van de Velde et al. 2004). The third signal (5.39/102.48 ppm), having ${ }^{1} J_{\mathrm{C} 1-\mathrm{H} 1}=173.5 \mathrm{~Hz}$, originated likely from an unknown a-linked glycan present in $\mathrm{FL}$ seaweeds, since our NMR data are different from those of the NMR of isolated starch (Knutsen and Grasdalen, 1987). The signals originating from the ring carbons of l-carrageenan were assigned from HSQC, COSY and TOCSY spectra. The signal at 4.93/74.42 ppm belongs to I-G4Sr 3 (Préchoux et al. 2014) and signals of a-glycan $(\mathrm{aG})$ are: $3.67 / 80.00$ ppm (2 aG), 3.97/76.26 ppm (3 aG), 3.85/74.10 ppm (4 aG), 3.67/74.47 ppm (5 aG) and 3.95, 4.00/63.68 ppm ( $6 \mathrm{aG})$. The peak corresponding to long-range spin-spin interaction across the inter-glycosidic linkage (4.67/80.09 ppm) between $\mathrm{H}-1$ of I-G4S and C-3 of t-DA2S unit was observed in HMBC (Fig. 2, right). The other four signals originated from the intra-ring interactions in t-carrageenan. 
Four anomeric signals were detected in HSQC spectrum of $\mathrm{k}$-carrageenan (Fig. 3, left). Two overlapping signals at 5.11/97.27 ppm originated from $\beta$ - and $\mathrm{k}-\mathrm{DA}$ units and 4.66/104.80 ppm from $\beta$-G and K-G4S units similarly to furcellaran (see Table S1). However, there was no signal at 4.14/66.70 ppm related to non-sulfated G4. This indicates the absence of $\beta$-carrageenan in $\mathrm{k}$-carrageenan sample. In addition, there was also a signal at 5.30/94.46 ppm corresponding to I-DA2S anomeric chemical shift (van de Velde et al. 2014). The low intensity of I-DA2S anomeric signal indicate the minor content of t-carrageenan in the $\mathrm{K}$-carrageenan sample. The fourth anomeric signal, which was already present in the spectrum of $\mathrm{t}$ carrageenan at 5.39/102.56 ppm, originated from a-glycan. The remaining signals were identical with those observed in HSQC spectrum of t-carrageenan (Fig. 2, left). The peaks corresponding to interglycosidic correlations between $\mathrm{k}-\mathrm{DA}\left(\mathrm{H}_{4}\right)$ and $\mathrm{k}-\mathrm{G} 4 \mathrm{~S}\left(\mathrm{C}_{1}\right)(4.61 / 104.81 \mathrm{ppm})$ and $\mathrm{k}-\mathrm{DA}\left(\mathrm{H}_{1}\right)$ and $\mathrm{k}-\mathrm{G} 4 \mathrm{~S}$ $\left(C_{3}\right)(5.11 / 81.53 \mathrm{ppm})$ were observed in HMBC (Fig. 2, right). These and other signals in HMBC (intra-ring proton-carbon interactions), are typical for $\mathrm{k}$-carrageenan. The presence of other peaks with low intensities in HSQC spectrum could not be reliably assigned from obtained HMBC data either due to a low concentration or due to high molecular weight (short $\mathrm{T}_{2}$ values). The $\mathrm{K}$-carrageenan polysaccharide showed different HSQC spectrum (Fig. 3), compared to one observed for K-carrageenan oligosaccharides (Yu at al. 2002). These results indicate the effect of high molecular weight of our samples on the shape of the NMR spectra.

The isolated FLW extract represents $44 \%$ yield from the Furcellaria lumbricalis specia. In this case following anomeric signals can be assigned in HSQC spectrum (Fig. 4, left; Table S1): $\lambda$-G2S

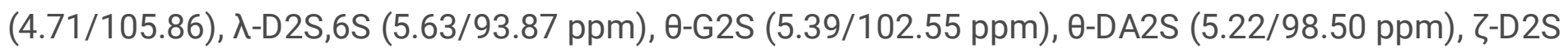
(5.23/94.77 ppm), 乙-G2S (4.71/105.84 ppm), $\mu$-D6S and v-D2S,6S (4.97/100.70 ppm), $\mu$ - and v-G4S $(4.49 / 106.18 \mathrm{ppm})$. These results are in agreement with previously published data (van de Velde at al. 2004). We note that these are solely sulphated units. This may be due to better water solubility of sulphated components (solubilized due to the ion-exchanging sulphate groups), as opposed to less sulphated carrageenans. Sulphur content of the FLW fraction (11.80 \%) further supports this theory. Similarly to previous cases (l- and K-carrageenan), the signal at 5.39/102.55 ppm originated from aglycan (Table S1 in supplementary information). The anomeric signal at 4.65/98.68 ppm was assigned to the к- $\beta-\kappa$ hybrid unit based on proton chemical shift at 4.67 ppm (G4Sr $\beta-H 1$ or G4Snr-H1 (Pelosi at al. 2003). The remaining ring signals were assigned similarly to previous cases (see Table $S 1$ in supplementary information). Additionally, the $\zeta-D 2 S$ unit showed identical anomeric signal as a-DA2S (5.23/94.77 ppm). Also observed was the (1-3)-a-G-G6S signal overlapping with $\theta-G 2 S$ signal $(5.39 / 102.55 \mathrm{ppm})$. The signal of a-carrageenan (a-G) was overlapping with signals of $\lambda-\mathrm{G} 2 \mathrm{~S}$ and $\zeta-\mathrm{G} 2 \mathrm{~S}$ (Table $\mathrm{S} 1$ in supplementary information). The signal at 3.90/102.54 ppm in HMBC originated from the intra-ring correlation between aG6S $\left(\mathrm{H}_{3}\right)$ and aG6S $\left(\mathrm{C}_{1}\right)$ and was overlapped with $\mathrm{aG}\left(\mathrm{H}_{3}\right) \rightarrow \mathrm{aG}\left(\mathrm{C}_{1}\right)$ correlation (3.92/102.60 ppm) (Fig. 4, right). Both of these observed correlations confirmed the presence of (1-3)-a-G-G6S glycan. 
Used sonication extraction method resulted in acceptable yield of Gigartina water-soluble extract (GSUW, $42 \%)$. The sample was extracted in the presence of $\mathrm{NaN}_{3}(1 \%)$ to prevent fungi degradation. This polysaccharide fraction showed seven signals and was analysed by COSY (not shown) and HSQC experiment (Fig. 5, left and Table S1). The anomeric signal resonated at 5.39/102.54 ppm, $\mathrm{H}_{6} / \mathrm{C}_{6}$ signal at 3.68-3.90/63.40 ppm, $\mathrm{H}_{2} / \mathrm{C}_{2}$ signal at 3.66/74.39 ppm and $\mathrm{H}_{3} / \mathrm{C}_{3}$ signal at 3.97/76.17 ppm. Similar analysis using TOCSY (not shown) and HSQC enabled the assignment of $\mathrm{H}_{4} / \mathrm{C}_{4}$ at 3.84/74.11 ppm and $\mathrm{H}_{5} / \mathrm{C}_{5}$ at 3.65/74.39 ppm. The other $\mathrm{H}_{6} / \mathrm{C}_{6}$ signal was detected at 4.32-4.35/72.08 ppm and likely originated from the sulphated $\mathrm{C}_{6}$ group. The $\mathrm{HMBC}$ experiment (Fig. 5, right) allowed the assignment of the signal at 5.41/76.16 ppm which originated from inter-glycosidic interaction $\left(\mathrm{H}_{1} \rightarrow \mathrm{C}_{3}\right)$ in the nonsulphated (1-3)-a-glycan unit. The signals at 5.38/74.11 ppm represent the $\left(\mathrm{H}_{1} \rightarrow \mathrm{C}_{5}\right)$, interaction; further intra-ring interactions across two or three bonds were identified: $3.97 / 79.92 \mathrm{ppm}\left(\mathrm{H}_{3} \rightarrow \mathrm{C}_{4}\right), 3.97 / 74.33$ ppm $\left(\mathrm{H}_{3} \rightarrow \mathrm{C}_{2}\right), 3.66 / 74.14 \mathrm{ppm},\left(\mathrm{H}_{4} \rightarrow \mathrm{C}_{5}\right), 3.66 / 76.15 \mathrm{ppm}\left(\mathrm{H}_{4} \rightarrow \mathrm{C}_{3}\right), 102.50 / 3.65 \mathrm{ppm}\left(\mathrm{H}_{2} \rightarrow \mathrm{C}_{1}\right)$, and $3.66 / 63.34 \mathrm{ppm}\left(\mathrm{H}_{5} \rightarrow \mathrm{C}_{6}\right)$. The a-anomer was compatible with the value ${ }^{1} J_{\mathrm{C} 1-\mathrm{H} 1}=173.5 \mathrm{~Hz}$. This result is supported by the NMR data of (1-3)- $\beta$-glucan run in $\left(\mathrm{CD}_{3}\right) \mathrm{SO}$ with chemical shift at $86.30 \mathrm{ppm}\left(\mathrm{C}_{3}\right.$; Pelosi et al. 2003). Observed value is ten ppm apart from our a-glycan $C_{3}$ signal run in $D_{2} O$. The water-solubility of our glycan with much higher molecular weight (see SEC-MALS section) indicates a dramatical difference in its physical properties. Relatively high value of the C- 6 chemical shift ( 6 aG6S 72.08 ppm), along with relatively high sulphur content of the fraction (11.94\%) support the assumption that C- 6 carbon of (1-3)-a-glycan is sulphated. Except for the furcellaran fraction, this polysaccharide was present in all the previous fractions. Based on ${ }^{1} \mathrm{H}-\mathrm{NMR}$ chemical shift of $\mathrm{C}_{6}$-sulphated signal is at 4.40 ppm observed for sulphated starch (Vega-Rios at al. 2014), we assume that our (1-3)-a-glycan is sulphated at $\mathrm{C}_{6}$ carbon (aG6S).

When GS was extracted using sonication under the carbonate-peroxide oxidative conditions (GSUCP), the fraction yield (63\%) increased in comparison to GSUW fractions. HSQC experiment (Fig. 6, left) enabled the assignment of the $\mathrm{aG}$ anomeric signals in (1-3)-a-glycan (5.40/102.50 ppm) as well as anomers in $\theta$ carrageenan (5.36/102.75 ppm, G2S and 5.22/98.42, DA2S). Besides the anomeric and ring signals, we also observed three types of $\mathrm{C}_{6}$ groups at 3.83, 3.87/63.39 (aG6), 3.78, 3.99/68.56 ( $\mu$-D6S) and 3.73, 4.15/70.36 ppm (v-D2S,6S) that are typical for the carrageenans. HMBC spectrum (Fig. 6, right) revealed two inter-ring correlations, particularly $\theta-\mathrm{G} 2 \mathrm{~S}\left(\mathrm{H}_{3}\right) \rightarrow \theta-\mathrm{DA} 2 \mathrm{~S}\left(\mathrm{C}_{1}\right)$ at $3.77 / 98.50 \mathrm{ppm}$ and $\theta-\mathrm{G} 2 \mathrm{~S}\left(\mathrm{H}_{1}\right) \rightarrow \theta$ DA2S $\left(\mathrm{C}_{3}\right)$ at 5.39/75.00 ppm, and two intra-ring correlations: $\mathrm{aG}\left(\mathrm{H}_{2}\right) \rightarrow \mathrm{aG}\left(\mathrm{C}_{1}\right)$ at 5.39/76.22 ppm and v$\mathrm{G} 4 \mathrm{~S}\left(\mathrm{H}_{1}\right) \rightarrow \mathrm{v}-\mathrm{G} 4 \mathrm{~S}\left(\mathrm{C}_{2}\right)$ at $4.98 / 72.57 \mathrm{ppm}$. These results suggest the GSUCP fraction contained (1-3)-a-GG6S glycan, $\theta$-carrageenan, and $\mu$ - and v-carrageenans hybrids without $v$ - and $\mu$-G $4 S$ HSQC signals at 4.49/106.18 ppm otherwise present in FLW fraction (Fig. 4). The GSUCP is a very mild extraction method with $184 \mathrm{~kJ}$ of total converted mechanical energy (see Methods) and produced the highest molecular weight fraction. This low-energy extraction process suggests the absence of the $\mu$-D6S and v-D2S,6S units is not related to the extraction-induced material degradation. Instead, we believe the reason for this 
is the presence of hybrids containing only the $\mu$-D6S and v-D2S,6S repeating units and not the $\mu-G 4 S$ and $\mathrm{v}$-G4S units typical for $\mu$ - and v-carrageenans. This assumption is supported by a complete absence of anomeric signals at 4.49/106.18 ppm in Fig. 6, otherwise observed in FLW extract containing $\mu$ - and vcarrageenans (Fig. 4). Also, there was no signal observed at $175 \mathrm{ppm}$ in the HMBC spectrum of GSUCP extract, which further supports the absence of oxidation products.

The GSW extraction resulted in the highest yield (68\%). Besides the signals observed in the previous fractions ( $\mathrm{aG}, \mathrm{aG} 6 \mathrm{~S}, \theta$-carrageenan), the signals originating from $\mathrm{a}-, \beta-, \mathrm{l}, \mathrm{K}$ - and $\zeta$-carrageenan were also present (Fig. 7, left) in this fraction. The absence of $\mu$ - and v-G4S anomeric signals indicate the presence of some hybrid, similarly to the case of GSUCP extract. HMBC spectrum (Fig. 7, right) revealed mainly inter-glycosidic bond correlations in $\theta$ - and $\mathrm{k}$-carrageenan indicating their predominance in the extract. The presence of $\beta$-carrageenan was confirmed by the two overlapping peaks present in HSQC spectrum at 5.10/97.10 and 5.11/97.70 ppm.

NMR results of all the seven studied samples indicate that GSW consisted of the most complicated mixture of $a-, \beta-, K-, L, \theta-, \zeta$-carrageenans, (1-3)-a-glycan partially sulfated at $C_{6}$, and $\mu$-D 6S and v-D2S,6S hybrids. Analysis of GSUW and GSUCP extracts showed that the sonication extraction method was the most selective and sensitive. We note the GSUW method yielded only the (1-3)-a-glycan predominantly sulphated at C6. The GSUCP extraction enabled separation of only three hybrids ( $\mu$-D6S, v-D2S,6S and (1-3)-a-glycan containing G6S groups) and resulting fraction lacked other known regular carrageenan structures. To the best of our knowledge, these three polysaccharides have not yet been observed in red algae seaweeds. No cellulose fragments could be detected in none of the seven analysed extracts. This is based on absence of known ${ }^{13} \mathrm{C}$ NMR chemical shifts of solubilized cellulose fragments at $103.50\left(\mathrm{C}_{1}\right)$ and $60.90 \mathrm{ppm}\left(\mathrm{C}_{6}\right)$ in comparison to our data (Table S1, resp. Toffanin at al, 1994).

\section{Sec-mals Analysis}

SEC-MALS results are summarized in Fig. 8. It compares molecular weight distribution (MWD) and conformation plot $R_{g}=f(M)$. MALS detector is an elastic or total intensity light scattering which determines macromolecule size (radius of gyration $R_{g}$ ) from the angular variation of the scattered light and potentially it is able to determine size $R_{g}$ when it assumes values greater than 10-20 nm depending from the specific conditions. Specifically, for the analyzed polysaccharides in the complex acidic aqueous solvent $(0.1 \mathrm{M}$ acetate buffer $\mathrm{pH} 4.5)$ the $\mathrm{R}_{\mathrm{g}}$ value is measured with sufficient accuracy in the range from $\approx 30 \mathrm{~nm}$ to $\approx 150 \mathrm{~nm}$. The conformation plot $\mathrm{R}_{\mathrm{g}}=\mathrm{K} \cdot \mathrm{M}^{\mathrm{a}}$ is the scaling law between macromolecules size $\left(R_{g}\right)$ and molecular weight $(M)$. Conformation plot is very important because is correlated to the macromolecules stiffness in solution and the thermodynamic strength of the solvent (good or poor or 
theta). Based on the slope of the conformation plot (a) there are these potential conformations: i) $a>0.5$ up to 0.6 flexible random coil in good solvent; ii) $a>0.6$ stiff, i.e. semi-rigid up to rigid rod; iii) $a<0.5$ low to $0.33 ; a=0.33$ is the slope of a compact sphere. Also macromolecules structure (linear or branched particularly long chain branching) has meaningful influence on slope value (a) and curvature of the conformation plot.

Analyzing data shown in Fig. 8 indicates meaningful differences between various samples in both MWD and molecular conformation. Multimodal chromatogram (three peaks) and different polymer conformation (macromolecules stiffness) of many samples demonstrate that they are mixture of polysaccharides with different macromolecular structure. SEC-MALS results are an important confirmation of NMR results.

MWD of K-, l-carrageenan and furcellaran (Fig. 8, upper panel) shows three peaks (i.e. three components) with molecular weight ranging from very high to relatively low. On the contrary, MWD of GSUCP, GSUW, FLW, and GSW (Fig. 8, bottom panel), with exception of FLW sample shows a single main peak with molecular weight ranging from very high to high. FLW sample show also a minor low molecular weight peak $\left(M_{p}=3.8 \mathrm{~kg} / \mathrm{mol}\right)$. Summary of the SEC-MALS results $\left(M_{p}\right.$ and Amount) for $\mathrm{K}$-, l-carrageenan and furcellaran is in Table 1.

Table 1

Summary SEC-MALS results of three samples.

\begin{tabular}{|lllllll|}
\hline Sample & \multicolumn{2}{l}{ Peak 1 (Main) } & Peak 2 & \multicolumn{3}{c|}{ Peak 3 } \\
\hline & $\begin{array}{l}\mathrm{M}_{\mathrm{p}} \\
(\mathrm{kg} / \mathrm{mol})\end{array}$ & $\begin{array}{l}\text { Amount } \\
(\%)\end{array}$ & $\begin{array}{l}\mathrm{M}_{\mathrm{p}} \\
(\mathrm{kg} / \mathrm{mol})\end{array}$ & $\begin{array}{l}\text { Amount } \\
(\%)\end{array}$ & $\begin{array}{l}\mathrm{M}_{\mathrm{p}} \\
(\mathrm{kg} / \mathrm{mol})\end{array}$ & $\begin{array}{l}\text { Amount } \\
(\%)\end{array}$ \\
\hline $\begin{array}{l}\mathrm{K}- \\
\text { carrageenan }\end{array}$ & 173.8 & 77.8 & 35.0 & 14.9 & 14.0 & 7,3 \\
\hline $\begin{array}{l}\text { t- } \\
\text { carrageenan }\end{array}$ & 264.4 & 87.0 & 56.0 & 8.6 & 11.9 & 4.4 \\
furcellaran & 144.0 & 75.6 & 15.4 & 16.8 & 4,3 & 7.6 \\
\hline
\end{tabular}

Average molecular weight results for $\mathrm{k}$-carrageenan are: $M_{n}=66.4 \mathrm{~kg} / \mathrm{mol}, M_{w}=143.3 \mathrm{~kg} / \mathrm{mol}$, polydispersity index $M_{w} / M_{n}=2.2$. Furcellaran assume these average values: $M_{n}=29.8 \mathrm{~kg} / \mathrm{mol}, M_{w}=153.5$ $\mathrm{kg} / \mathrm{mol}, M_{w} / M_{n}=5.2$.; very broad polydispersity $\left(M_{w} / M_{n}>5\right)$ indicate presence of several fractions different in molecular weight and structure. The t-carrageenan sample has higher molecular weight than K-carrageenan and furcellaran: $M_{n}=110.2 \mathrm{~kg} / \mathrm{mol} ; M_{w}=296.8 \mathrm{~kg} / \mathrm{mol} ; M_{w} / M_{n}=2.7$.

Summary of the SEC-MALS results $\left(M_{p}, M_{w}, M_{w} / M_{n}\right)$ of GSUCP, GSUW, FLW, and GSW extracts are in Table 2. 
Table 2

Summary SEC-MALS results four extracts.

\begin{tabular}{|lllll|}
\hline Sample & $M_{\mathbf{p}}$ & $M_{n}$ & $M_{\mathbf{w}}$ & $\mathbf{M}_{\mathbf{w}} / M_{\mathbf{n}}$ \\
\hline & $\mathrm{kg} / \mathrm{mol}$ & $\mathrm{kg} / \mathrm{mol}$ & $\mathrm{kg} / \mathrm{mol}$ & \\
\hline GSW & 77.8 & 61.1 & 158.5 & 2.6 \\
\hline GSUW & 564.6 & 305.5 & 479.8 & 1.6 \\
\hline GSUCP & 994.0 & 430.5 & 1373.5 & 3.2 \\
\hline FLW & 497.7 & 311.9 & 531.0 & 1.7 \\
\hline
\end{tabular}

According to SEC-MALS results the peak molecular weight $M_{p}$ decrease: GSUCP $(994 \mathrm{~kg} / \mathrm{mol})>$ GSUW $(565 \mathrm{~kg} / \mathrm{mol})>\mathrm{FLW}(498 \mathrm{~kg} / \mathrm{mol})>\mathrm{t}$-carrageenan $(264 \mathrm{~kg} / \mathrm{mol})>\mathrm{k}$-carrageenan $(174 \mathrm{~kg} / \mathrm{mol})>$ furcellaran $(144 \mathrm{~kg} / \mathrm{mol})>\mathrm{GSW}(78 \mathrm{~kg} / \mathrm{mol})$. GSUCP fraction show the highest molecular weight and the biggest size of coil, than GSUW and FLW. The lowest SEC-MALS values were determined for the GSW extract. This resulted from use of sonication method in combination with carbonate/peroxide dissolution potential as opposed to just pure water reflux treatment.

Conformation of k-carrageenan macromolecules, Fig. 8 upper panel, substantially correspond to flexible random coil (slope of conformation plot $\mathrm{a}=0.54$ ). Conformation of $\mathrm{t}$-carrageenan is much less flexible respect to $\mathrm{k}$-carrageenan up to nearly compact sphere. Conformation of furcellaran macromolecules is substantially flexible, only a little more compact respect to k-carrageenan. In conformation analysis it should be considered that the presence of some extent of molecular aggregation in the aqueous acidic solvent $(\mathrm{pH}=4.5)$ could influence results in particular for $\mathrm{t}$-carrageenan compact polysaccharide. Conformation of four extracts is quite different, varying between $\mathrm{k}$-carrageenan (flexible) and tcarrageenan (compact).

\section{Xrd Analysis}

Symmetric XRD scans were measured on all samples to study the presence of cellulose; Fig. 9 presents the acquired data and shows very different diffraction pattern for each sample, however mostly amorphous character and virtually no cellulose content can be concluded in all cases. The latter was corroborated by our NMR results discussed in previous sections.

XRD trace of the GSUCP film (topmost profile in Fig. 9) showed a slight resemblance of ball-milled cotton cellulose II (Nam et al., 2016), i.e. with diffraction maxima 110 and $020\left(2 \theta=\sim 21^{\circ}\right)$ with very broad full width at half maximum (FWHM), however no signal corresponding to 110 reflection was observed. This means significant cellulose II content can be ruled out. Similarly, due to the lacking 110 and 110 reflections at corresponding $2 \theta$ positions, significant cellulose $I \beta$ content in the GSUCP film was unlikely ( $N a m$ et al., 2016). We note this fraction was extracted with $\mathrm{Na}_{2} \mathrm{CO}_{3} / \mathrm{H}_{2} \mathrm{O}_{2}$ method at room temperature and SEC-MALS analysis confirmed the highest molecular weight of all samples. This indicates the 
observed XRD pattern corresponds to the presence of some non-cellulosic amorphous polysaccharide(s) with a broad diffraction peak centered at $2 \theta=\sim 21^{\circ}$. Similar results were obtained for the extract of Antarctic algae Cystosphaera jacquinottii (Paniz et al., 2020). Reported data on this specia confirmed $5 \%$ content of cellulose before extraction.

The shape of FLW XRD profile (second from top) showed an additional maximum centered at $2 \theta=$ $14^{\circ}-16^{\circ}$. This could be related to the diffraction maxima of cellulose I (diffraction indices 110 and110), however no signal was observed for the most intense peak corresponding to 220 reflection centered at $2 \theta$ $=\sim 23^{\circ}$ (French, 2014). Therefore, we believe this feature was related to some non-cellulose polysaccharide.

XRD profile of GSW film (third from top) was almost identical to that of GSUCP with the exception of a weak shoulder at $2 \theta \sim 6^{\circ}$ unrelated to cellulose.

GSUW (fourth from top) profile showed similar shape to FLW (second from top), however somewhat lower intensity of the main band was observed; no traces of cellulose were concluded. This reflects the low extraction power of used ultrasound treatment, which was unable to extract cellulose from the substrate.

Similarly to previous samples, the three remaining XRD profiles, i.e. furcellaran (third from bottom), tcarrageenan (second from bottom), and k-carrageenan (first from bottom) showed diffraction maxima unrelated to neither of the two types of cellulose, confirming our NMR results.

\section{Pf-qnm Analysis}

In this section, we present surface morphology and surface mechanical properties of all seven films. RMS surface roughness and correlation lengths where applicable and reduced modulus, stiffness, and adhesion quantities were determined. Due to the large variations in spatially-resolved measured mechanical properties resulting, e.g. from AFM tip contact area variations close to the edges of surface features, all PF-QNM-derived quantitative properties, i.e. reduced modulus, stiffness, and adhesion were evaluated from reduced scan areas $(100 \times 100 \mathrm{~nm})$ selected from presented $1 \mu \mathrm{m} \times 1 \mu \mathrm{m}$ and $2 \mu \mathrm{m} \times 2 \mu \mathrm{m}$ scans. Several (3-5) reduced areas were chosen across each scan; Showed quantitative data represent mean values derived from all reduced areas in each sample. Bar charts in Fig. 14a- d show a comparison of determined values of RMS surface roughness, reduced modulus, stiffness and adhesion for all samples. Surface topography maps and spatially-resolved mechanical properties are showed and discussed in detail in following sections.

\section{Topography}

Figure 10a) - g) show representative surface topography scans of all studied samples. 1D line profiles corresponding to white horizontal lines are also shown. Values of RMS surface roughness and correlation 
lengths, where applicable, were determined from $2 \mu \mathrm{m} \times 2 \mu \mathrm{m}$ topography scans. In case of grainy surface, correlation length represents the average diameter of particles observed in the surface topography scans. Determined surface roughness values were increasing in following order: FLW $(2.4 \mathrm{~nm})<$ GSUCP $(3.6 \mathrm{~nm})$ $<$ k-carrageenan $(5.2 \mathrm{~nm})<$ l-carrageenan $(5.5 \mathrm{~nm})<$ GSW $(8.0 \mathrm{~nm})<$ GSUW $(14.0 \mathrm{~nm})<$ furcellaran $(18.6$ $\mathrm{nm})$. Correlation lengths were determined only for samples, where grainy surface was observed, i.e. $\mathrm{k}$ carrageenan, t-carrageenan, and furcellaran and their values are presented and discussed in the next section.

We also note that circular particles with mean diameter of $\sim 80 \mathrm{~nm}$ and mean height of $\sim 20 \mathrm{~nm}$ were observed scattered across the GSW sample surface (e.g. shown in the bottom of Fig. 10b) with concentration of $\sim 2.3 \times 10^{8} \mathrm{~cm}^{-2}$, which were likely extraction-related residues. Based on the values of gyration radii $\left(R_{g}\right)$ determiend by SEC-MALS analysis we conclude that surface roughness and correlation lengths are related to polysaccharide coil dimensions.

\section{Reduced Modulus}

Size and distribution of macromolecular coils constituting the polysaccharide films can significantly affect their mechanical properties, therefore in this section we compare reduced moduli of our samples with the determined values of gyration radii $\left(R_{g}\right)$ and correlation lengths $(T)$. Correlation lengths and partially also surface roughness are related to polysaccharide coil dimensions expressed by gyration radii of the seaweed fractions. AFM-determined correlation lengths were found to be in good agreement with $\mathrm{R}_{\mathrm{g}}$ values of polysaccharide coils obtained from SEC-MALS analysis.

Reduced modulus maps of all studied samples are shown in Fig. 11a) $-\mathrm{g}$ ). Average moduli values extracted from reduced $100 \times 100 \mathrm{~nm}$ areas in ascending order were: t-carrageenan $(24 \pm 4.5 \mathrm{MPa})<\mathrm{GSW}$ $(378 \pm 87 \mathrm{MPa})<\mathrm{k}$-carrageenan $(433 \pm 186 \mathrm{MPa})<\mathrm{GSUCP}(807 \pm 360 \mathrm{MPa})<$ furcellaran $(817 \pm 224$ $\mathrm{MPa})<\mathrm{GSUW}(822 \pm 262 \mathrm{MPa})<\mathrm{FLW}(1685 \pm 575 \mathrm{MPa})$. Figure 12 (a) shows reduced modulus map of $\mathrm{t}-$ carrageenan; similar to topography scan (Fig. 11 (a), coil-like structures packed close to each other were observed. According to SEC-MALS, for the main fraction with molecular weight at the peak $M_{p} 264$ $\mathrm{kg} / \mathrm{mol}$ and the $R_{\mathrm{g}}$ values (50-80 nm) observe only in fraction of $M_{w}$ from 264 to $1800 \mathrm{~kg} / \mathrm{mol}$, is in the range of calculated correlation length $T=57.7 \pm 3.2 \mathrm{~nm}$. Reduced modulus map of GSW film is shown in Fig. 12 (b). This film consisted of $a-, \beta-, k-,-, \theta-, \zeta$-carrageenans, (1-3)-a-glycan partially sulfated at $C_{6}$, and $\mu$-D6S and v-D2S,6S hybrid polysaccharides. This fraction has the smallest $M_{p}$ at $7 \mathrm{~kg} / \mathrm{mol}$ and we think it is the reason that no coil-like particles were observed in this case. According to SEC-MALS analysis the observed $R_{g}$ values at $40-55 \mathrm{~nm}$. For GSW $M_{p}$ value is too small and consequently the $R_{g}$ value is already too small to be considered as exact. For that reason we think that for such small molecular weigh the polysaccharide do not form the coil conformations. Value of GSW reduced modulus was more than one order of magnitude lower (24 MPa vs $378 \mathrm{MPa}$ ). The k-carrageenan fraction consisted of $\mathrm{K}-, \beta-\mathrm{l}$-carrageenan, and (1-3)-a-glycan partially sulfated at $\mathrm{C}_{6}$. Its correlation length $\mathrm{T}=$ 
$43.6 \pm 2.7 \mathrm{~nm}$ and according to $M_{p} 173 \mathrm{~kg} / \mathrm{mol}$ and $R_{g}=40-150 \mathrm{~nm}$ is higher than for l-carrageenan, although it is a component of $\mathrm{K}$-carrageenan fraction blend. In this case, coils were less closely packed when compared to those of $\mathrm{t}$-carrageenan. Reduced modulus of furcellaran increased to $817 \mathrm{MPa}$ and correlation length was $T=85.3 \pm 5.7 \mathrm{~nm}$, which agreed with $R_{g}=40-100 \mathrm{~nm}$ measurable only from $M_{p}$ $140 \mathrm{~kg} / \mathrm{mol}$. The GSUW film image showed most of the surface without coils. According to SEC-MALS analysis of (1-3)-a-glycan partially sulfated at $C_{6}$, the coil dimensions $R_{g}=45-120 \mathrm{~nm}$ observed at 120$800 \mathrm{~kg} / \mathrm{mol}$. Reduced modulus of GSUCP composite film (Fig. 12f) was $807 \mathrm{MPa}$ and $\mathrm{R}_{\mathrm{g}}=100-135 \mathrm{~nm}$ observed at range from $M_{w} 700-6000 \mathrm{~kg} / \mathrm{mol}$. The FLW film showed the highest reduced modulus (1685 $\pm 575 \mathrm{MPa}$ ) in relation to $R_{\mathrm{g}}=45-120 \mathrm{~nm}$ observed at $\mathrm{M}_{\mathrm{w}}$ range $180-1300 \mathrm{~kg} / \mathrm{mol}$. The fluctuation of the parameters could be explained by broader distribution of the coil volumes due the $M_{w} / M_{n}$ distribution.

\section{Stiffness}

Stiffness reflects the measure of resistance to deformation and factors mechanical properties of the material and its shape. According to average stiffness values extracted from $100 \times 100 \mathrm{~nm}$ reduced areas of PF-QNM-determined stiffness maps, these were increasing in following order: t-carrageenan $(0.8 \pm 0.1$ $\mathrm{N} / \mathrm{m})<\mathrm{k}$-carrageenan $(10.7 \pm 3.2 \mathrm{~N} / \mathrm{m})<\mathrm{GSW}(11.5 \pm 1.7 \mathrm{~N} / \mathrm{m})<$ furcellaran $(13.2 \pm 2.4 \mathrm{~N} / \mathrm{m})<\mathrm{GSUCP}$ $(13.4 \pm 3.8 \mathrm{~N} / \mathrm{m})<$ GSUW $(14.4 \pm 3.0 \mathrm{~N} / \mathrm{m})<\mathrm{FLW}(23.1 \pm 5.5 \mathrm{~N} / \mathrm{m})$. The order is similar as in case of reduced modulus, but with exchanged order for GSW and k-carrageenan, and furcellaran and GSUCP. However, due to the measurement uncertainty, these differences were negligible. Compared to the majority of GSW surface, slightly lower stiffness was observed for sparsely distributed isolated circular grains (Fig. 12b), typically $~ 7.9 \pm 1.5 \mathrm{~N} / \mathrm{m}$. Determined stiffness maps for all studied samples are shown in Fig. 12a-g).

\section{Adhesion}

Determined adhesion maps detail work of adhesion required for AFM tip to detach from the surface of the sample on each measured pixel. Capillary, electrostatic, or van der Waals forces are some of the typical sources of adhesion at the nanoscale. Determined adhesion maps for all samples are shown in Fig. 13a-g. Average adhesion forces extracted from $100 \times 100 \mathrm{~nm}$ areas for studied composite films were in following ascending order: $\mathrm{k}$-carrageenan $(4.5 \pm 1.7 \mathrm{nN})<\mathrm{l}$-carrageenan $(4.7 \pm 2.1 \mathrm{nN})<$ furcellaran $(7.3$ $\pm 1.3 \mathrm{nN})<\operatorname{GSUW}(9.4 \pm 1.0 \mathrm{nN})<\mathrm{GSUCP}(14.5 \pm 1.3 \mathrm{nN})<\mathrm{FLW}(15.0 \pm 3.1 \mathrm{nN})<\mathrm{GSW}(22.1 \pm 2.8 \mathrm{nN})$. The order is similar to reduced modulus and stiffness, with the difference that GSW showed the highest adhesion from all samples. Contrary to the majority of GSW surface due to smallest $\mathrm{M}_{\mathrm{p}}$, sparsely distributed isolated circular grains showed much lower average values of adhesion, typically $\sim 6.5 \pm$ $1.6 \mathrm{nN}$. Largest variations in adhesion across the surface of calculated adhesion maps were observed for GSW, GSUW, and GSUCP films. This fractions have the biggest $M_{p}$ values and various amounts of hybrids, which constituted these films. Large variations in topography in case of sample GSUW may also be partially responsible. 
The values of composite films roughness, reduced modulus, stiffness and adhesion are on Fig. 14. According to AFM analysis using PF-QNM methodology there is relation between $\mathrm{R}_{\mathrm{g}}$ values, corresponding $M_{p}$ values and topography roughness, reduced moduli, stiffness and adhesion parameters. There is certain optimum between molecular weight and the coil dimensions of individual types of polysaccharides in the bland. The biggest surface roughness of furcellaran and GSW might be due to the second smallest $M_{p}$ values in comparison to other fractions. The opposite situation occurred for reduced modulus of FLW fraction when the second biggest $M_{p}$ was observed. Also for stiffness parameter the highest value was observed on FLW. For adhesion parameter the highest value observed on GSW fraction indicates the smallest $M_{p}$ and $R_{g}$ values are affecting the adhesion process the most.

\section{Conclusions}

Physical, chemical, and mechanical properties of red algae seaweeds films prepared from FL and GS sources differing in type and content of carrageenans were extensively studied. NMR data showed that GSUW extraction was able to isolate only (1-3)-a-glycan 6-sulfate. GSUCP extraction resulted in a mixture of the same glycan and carrageenan hybrids $\mu$-D6S and v-D2S,6S observed for the first time in this study. FLW fraction was the only one which was found to contain $\mu$-and v-carrageenans. GSW extract contained only (1-3)-a-G6S glycan and $\mu$-and v-carrageenan hybrids without $\mu$ - and v-G4S units. The SEC-MALS analysis confirmed the highest polysaccharide molecular weight and $\mathrm{R}_{\mathrm{g}}$ values of polysaccharide coils in GSUW and GSUCP extracts. XRD analysis confirmed no cellulose content in all prepared films. Observed values of surface roughness, reduced moduli, stiffness, and adhesion provided by AFM and PF-QNM analyses indicated complex behavior of studied polysaccharide films affected by the values of $R_{g}$ of polysaccharide coils in relation to $M_{w}$ range of individual fractions where the gyration radii were observed. The calculated correlation lengths were in good agreement with measured $R_{g}$ values. Furcellaran film showed the highest surface roughness, while FLW showed the lowest. This was affected by the value of $M_{p}$, which was high for FLW and low for furcellaran, even though the $R_{g}$ values were similar. This indicates that furcellaran macromolecules on the surface of the film tend to loose water much quicker than FLW. It is also likely, that the amount polysaccharides in form of coils was smaller in case of furcellaran when compared to the FLW fraction. This factor could also affect the observed reduced moduli, where FLW showed the highest values due to best mechanical properties. Similar situation was found for determined values of stiffness of studied films. The highest adhesion value was found for GSW fraction with the smallest $M_{p}$ and $R_{g}$ values. All studied films are biocompatible and suitable for medical applications as heparin analogues or SARS-CoV-2 inhibitors (Kwan at al., 2020).

\section{Declarations}

\section{Acknowledgements}


This work was supported by the Grant Agency of Slovak Academy of Sciences VEGA grant \# 2/0022/18 and grant \# 2/0100/21. We thank to Dr. Svein H. Knutsen for support, Dr. Zuzana Netriová for running the TG/DTG/DTA experiments, and Alžbeta Kanská for the elemental analysis.

Author contributions: IŠ designed research; IŠ, FG, RM, AGS, DP, ED, and MH performed research; IŠ, FG, $\mathrm{RM}, \mathrm{ED}$, and $\mathrm{MH}$ analyzed data; IŠ and FG wrote the paper and all the co-authors edited the manuscript.

\section{Compliance with Ethical Standards}

Disclosure of potential conflicts of interest

The authors declare no conflict of interest, financial or otherwise.

Research involving Human Participants and/or Animals

There were no human participants and/or animals involved in the research process.

Informed consent

The authors do agree with the ethical standards of the journal as listed in submission guidelines in section Ethical Responsibilities of Authors.

\section{References}

Ciancia M, Matulewicz MC, Finch P, Cerezo AS (1993) Determination of structures of cystocarpic carrageenans from Gigartina skottsbergii by methylation analysis and NMR spectroscopy. Carbohydr Res 238: $241-248$.

Dyrby M, Petersen RV, Lersen J, et al (2004). Toward on-line monitoring of the composition of commercial carrageenan powders. Carbohydr Pol 57:337-348. http://doi.org/j.carbpol.2004.05.015

Ficko-Blean E, Préchoux A, Thomas F, at al (2017) Carrageenan catabolism is encoded by a complex regulon in marine heterotropic bacteria. Nature Communications 8:1685. http://doi.org/10.1038/s41467017-01832-6

French, A. D. (2014) Idealized powder diffraction patterns for cellulose polymorphs. Cellulose 21:885-896. http://doi.org/10.1007/s10570-013-013-0030-4

Gavara N, (2017) A beginner's guide to atomic force microscopy probing for cell mechanics. Microscopy Research and Technique 80 75-84.

Guibet M, Kervarec N, Génicot S, Chevolot Y, Helbert W (2006) Complete assignment of ${ }^{1} \mathrm{H}$ and ${ }^{13} \mathrm{C}$ NMR spectra of Gigartina skottsbergii $\lambda$-carrageenan using carrabiose oligosaccharides prepared by enzymatic hydrolysis. Carbohydr. Res. 341:1859-1869. 
He J, Xu Y, Chen H, Sun P (2016) Extraction, structural characterization, and potential antioxidant activity of the polysaccharides from four seaweeds. Int J Mol Sci 17:1988.

Johnson KL, Kendall K, Roberts AD (1971) Proceedings of the Royal Society of London, A 324301.

Kaemmer SB (2011) Introduction to ScanAsyst and PeakForce Tapping.

https://www.spmtips.com/afm-tip-HQ-NSC15-Al-BS

http://gwyddion.net/documentation/user-guide-en/statistical-analysis.html

Knutsen SH, Grasdalen H (1987) Characterization of water-extractable polysaccharides from Norwegian Furcelaria lubricalis (Huds.) Lamour. (Gigartinales, Rhodophyceae) by IR

and NMR spectroscopy. Bot Marina 30:497-505.

Kwon PS, Oh H, Kwon S-J, at al (2020) Sulfated polysaccharides effectively inhibit SARS- CoV-2 in vitro. Cell Discovery, 6, 1-4. https://doi.org/10.1038/s4121-020-00192-8

Marangoni Júnior L, Vieira RP, Jamróz E, Anjos CAR (2021) Furcellaran: an innovative biopolymer in the production of films and coatings. Carbohydr Polym 252:117221.

http://doi.org/10.1016/j.carbpol.2020.117221

Mirzadeh M, Arianejad MR, Khedmat L (2020) Antioxidant, antiradical, and antimicrobial activities of Polysaccharides obtained by microwave-assisted

extraction method: A review. Carbohydr Pol 229:115421. http://doi.org/10.1016/j.carbpol.2020.115421

Nam, S., French, A. D., Condon, B. D., Concha, M. (2016) Segal crystallinity index revisited by the simulation of X-ray diffraction patterns of cotton cellulose I $\beta$ and cellulose II. Carbohydr Polym 135:1-9. http://dx.doi.org/10.1016/j.carbpol.2015.08.035

Nečas D, Klapetek, P. (2012) Gwyddion: an open-source software for SPM data analysis. Central European Journal of Physics, 10, 181-188.

Paniz OG, Pereira CMP, Pacheco BS, at al (2020) Cellulosic materials obtained from Antarctic algae biomass. Cellulose 27:113-126. http://doi.org/10.1007/s10570-019-02794-2

Pelosi L, Imai T, Chanzy H, Heux L, at al (2003). Structural and morphological diversity of (1-3)- $\beta$-Dglucans synthesized in vitro by enzymes from Saprolegnia monoica.

Comparison with a corresponding in vitro product from blackberry (Rubus fruticosus). Biochemistry 42:6264-6274.

Pittenger B, Slade A, Berquand A (2013), Bruker Application Note AN141, i, 1-10. 
Pujol CA, Scolaro LA, Claucia M, at al (2006) Antiviral activity of carrageenan from Gigartina Skottsberii against intraperitoneal murine herpes simplex virus infectia.

Planta Medica 72:121-125.

Sader JE, et al. (2012) Review of Scientific Instruments 83, 103705, doi: 10.1063/1.4757398 https://sadermethod.org

Sedayu BB, Cran MJ, Bigger SW (2019) A review of property enhancement techniques for carrageenanbased films and coatings. Carbohydr Pol 216:287-302. http://doi.org/10.1016.2019.04.021

Schafer L, Usov I, Mezzenga R (2015) Anomalous stiffening and ion-induced coil-helix transition of carrageenans under monovalent salt conditions. Biomacromolecules, 16, 985-991.

http://doi.org/10.1021/bm501974k

Sun T, Tao H, Xie J, Zhang S, Xu X (2010) Degradation and antioxidant activity of k- carrageenans. J Appl Pol Sci 117:194-199.

Šimkovic I, Raab M, Mendichi R, Manová, A. Giacometti Schieroni, and M. Hricovíni Heparin composition: calculation based on elemental analysis and NMR data. Chem Pap 74:349-355. http://doi.org/10.1007/s11696-019-00957-w

Šimkovic I (2013) Unexplored possibilities of all-polysaccharide composites. Carbohydr Polym 95:697715. http://dx.doi.org/10.1016/j.carbpol.2013.03.040

Šimkovic I, Tracz A, Kelnar I, Uhliariková I, Mendichi R (2014) Quaternized and sulfated xylan derivative films. Carbohydr Polym 99: 356-364. http://dx.doi.org/10.1016/j.carpol.2013.08.075

Toffanin R., Knutsen SH, Bertocchi C, Rizzo R, Murano E (1994) Detection of cellulose in the cell wall of some red algae by ${ }^{13} \mathrm{C}$ NMR spectroscopy. Carbohydr Res 262:167-171.

Truus K, Vaher M, Usov Al, Pehk T, Kollist A (1997) Gelling galactans from the algal community of Furcellaria lubricallis and Coccotylus truncatus (the Baltic Sea, Estonia): a structure-property study. Int J Biol Macromolecules 21:89-96.

Usov Al (2011) Polysaccharides of the red algae. Adv Carbohydr Chem Biochem 65:115-217.

Usov I, Nyström, G, Adamcik J, Handschin S, Schütz Ch, Fall A, Bergström L, Mezzenga R (2015) Understanding nanocellulose chirality and structure-properties relationship at the single fibril level. Nature Communications 6:7564. http://dx.doi.org/10.1038/ncomms8564

van de Velde F, Pereira L, Rollema HS (2004) The revised NMR chemical shift data of carrageenans. Carbohydr Res 339:2309-2313. 
Vega-Rios A, Olmedo-Martínez JL, Farías-Mancilla B, at al (2014). Synthesis and electrical properties of polyaniline/iota-carrageenan biocomposites. Carbohydr Polym 110:78-86.

http://doi.org/10.1016/j.carbpol.2014.03.068

Yu G, Guan H, loanoviciu AS, at al (2002) Structural studies on k-carrageenan derived oligosac- charides. Carbohydr Res 337:433-440.

\section{Figures}

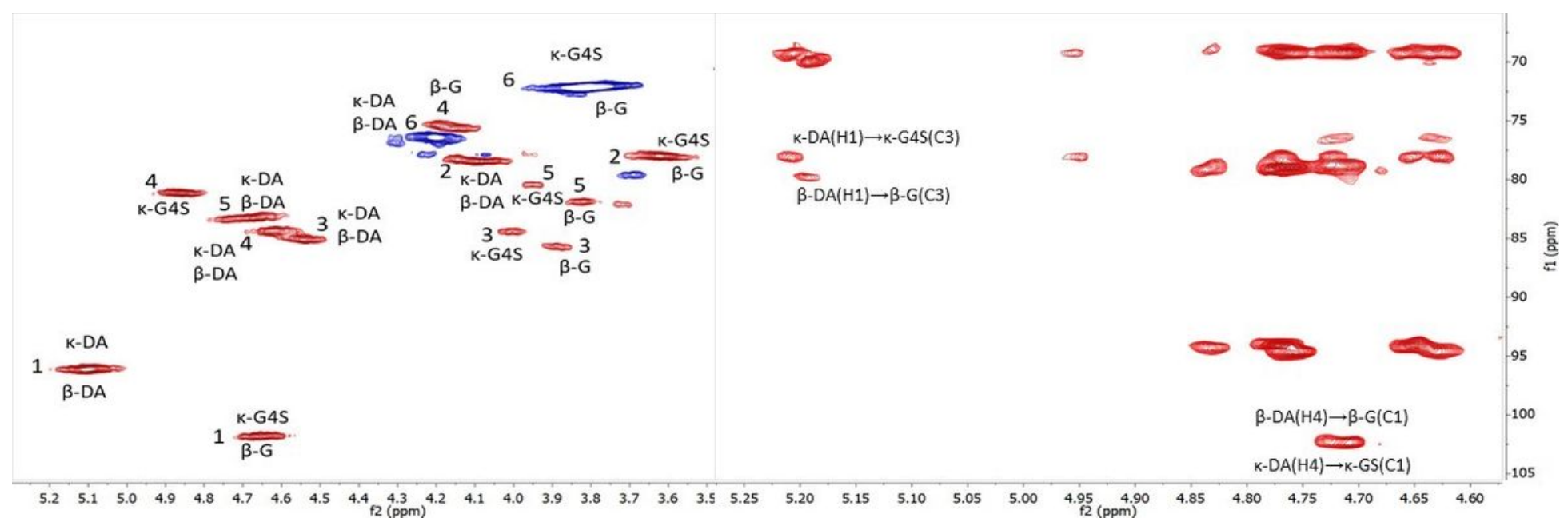

Figure 1

HSQC (left) and HMBC (right) spectra of furcellaran

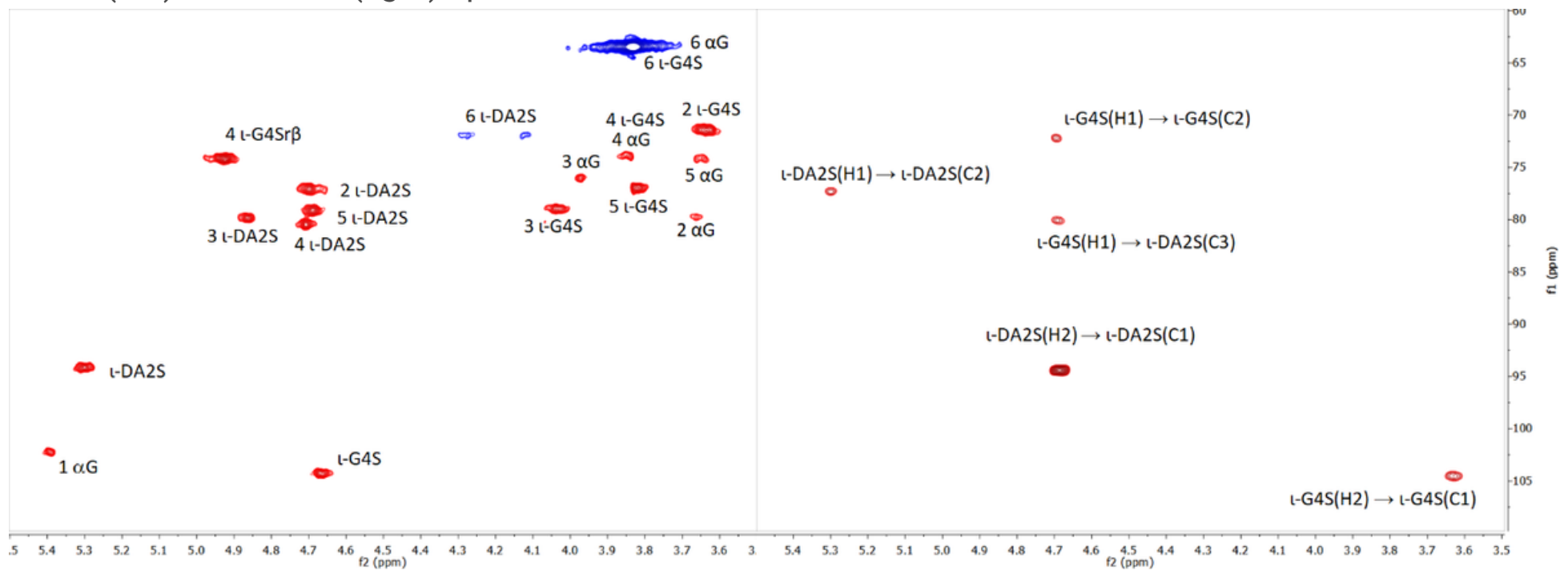

Figure 2

HSQC (left) and HMBC (right) spectra of t-carrageenan 


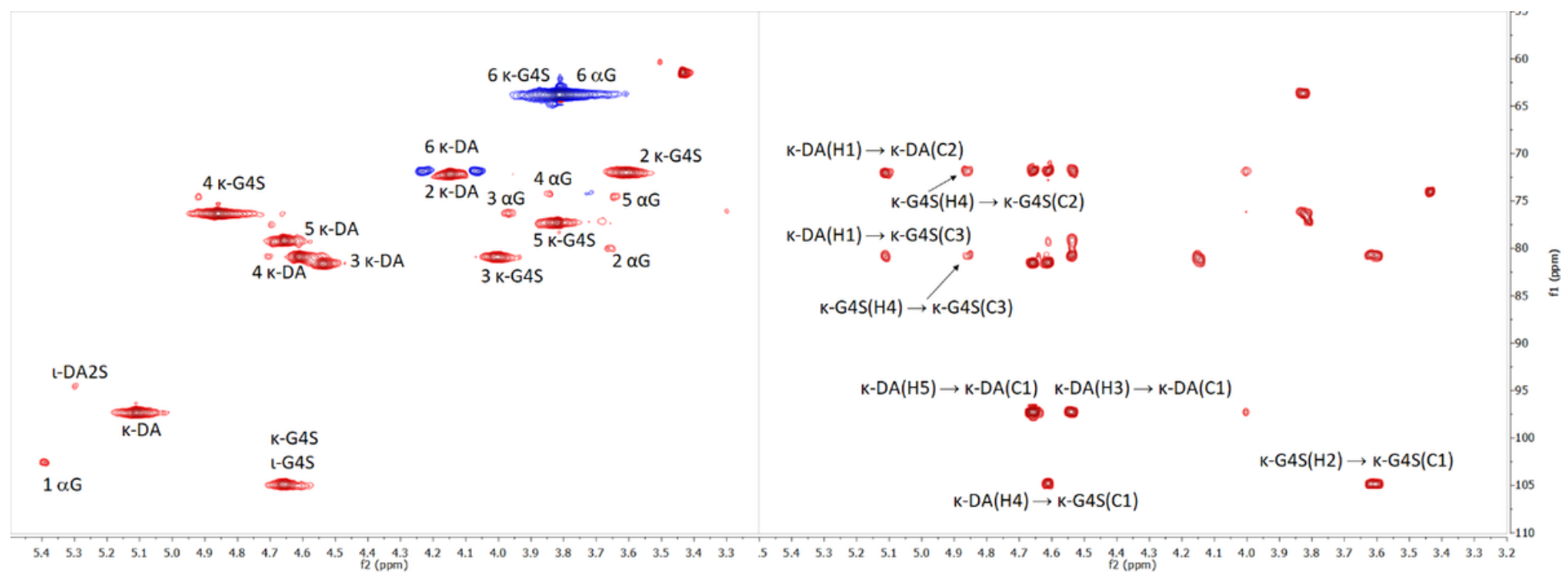

\section{Figure 3}

HSQC (left) and HMBC (right) spectra of K-carrageenan

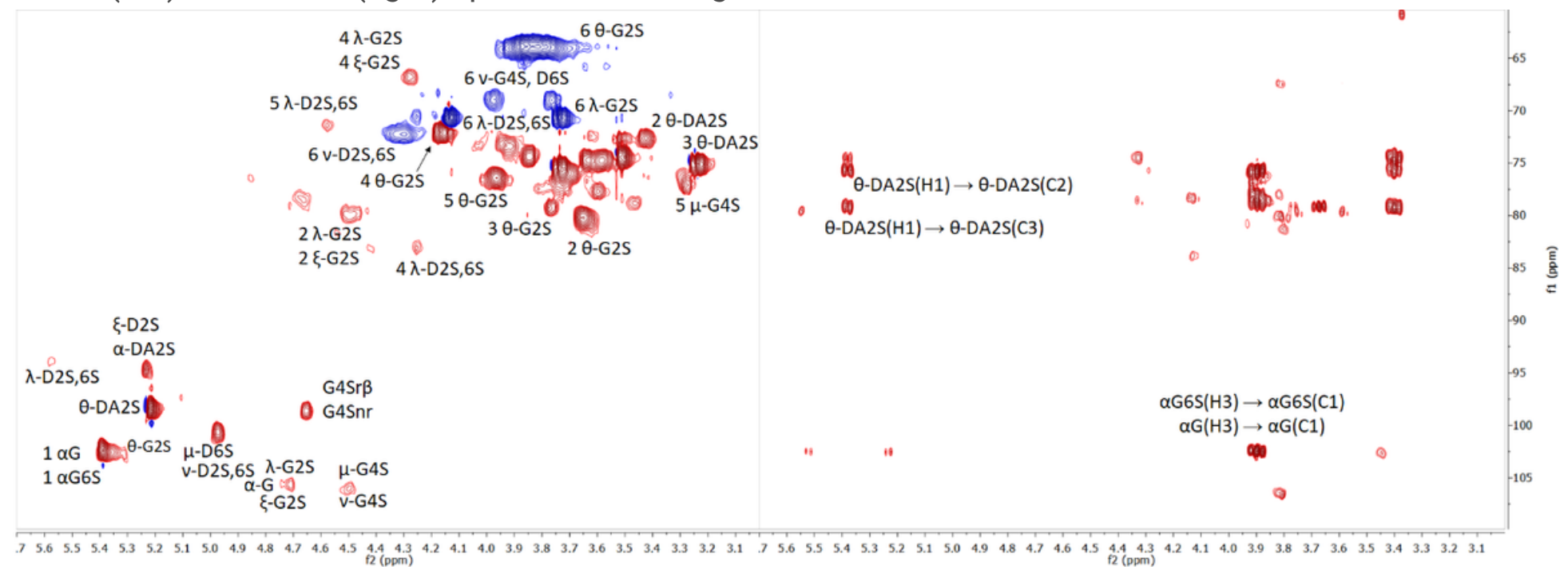

\section{Figure 4}

HSQC (left) and HMBC (right) spectra of FLW fraction 


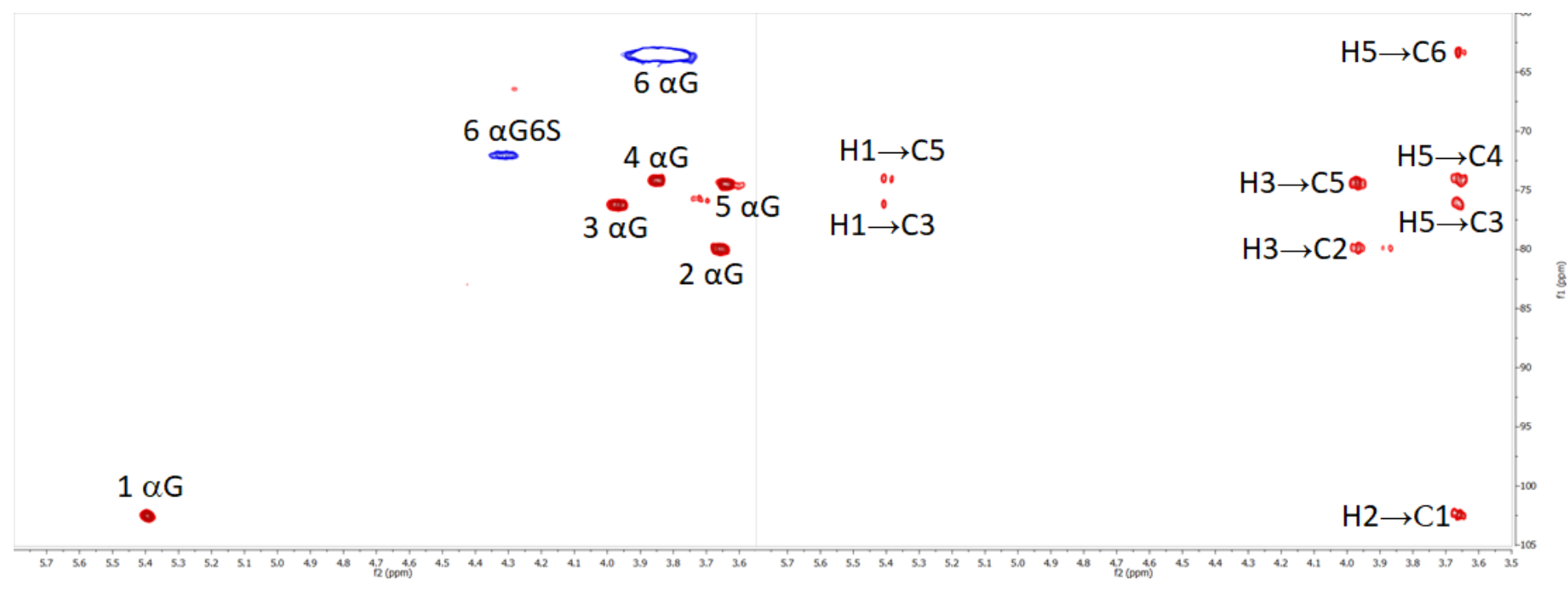

Figure 5

HSQC (left) and HMBC (right) spectra of GSUW

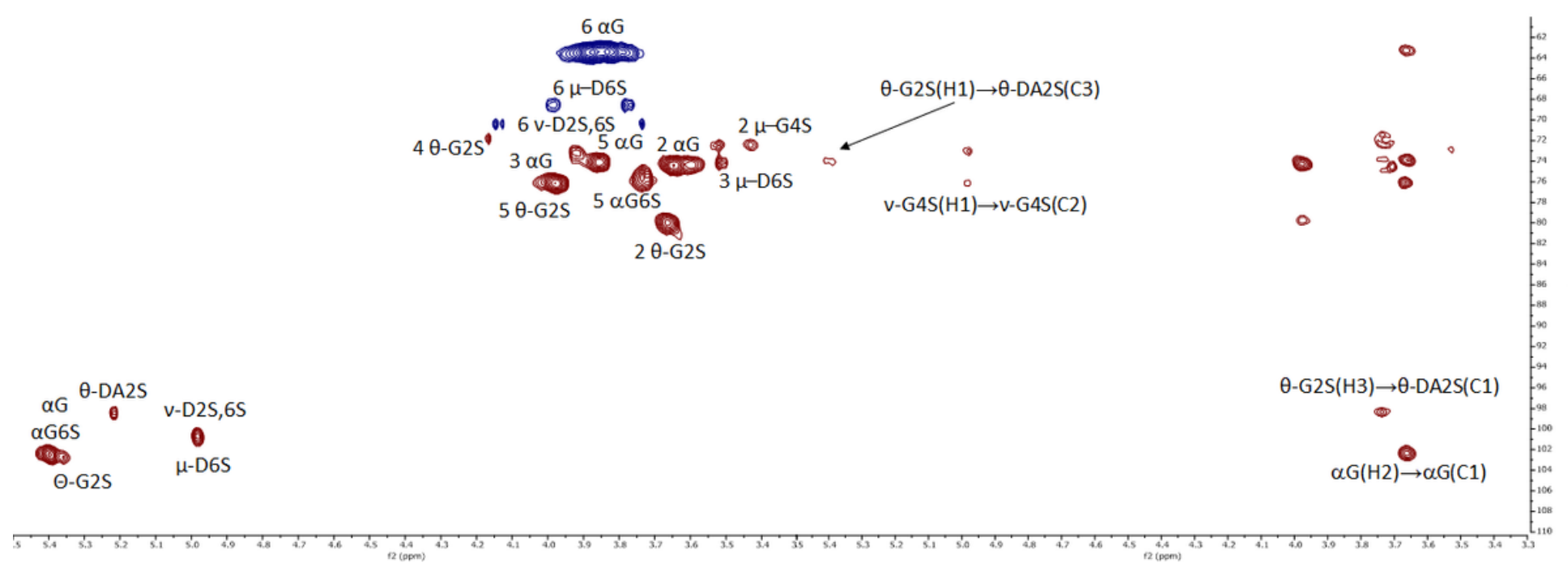

\section{Figure 6}

HSQC (left) and HMBC (right) spectra of GSUCP extract 


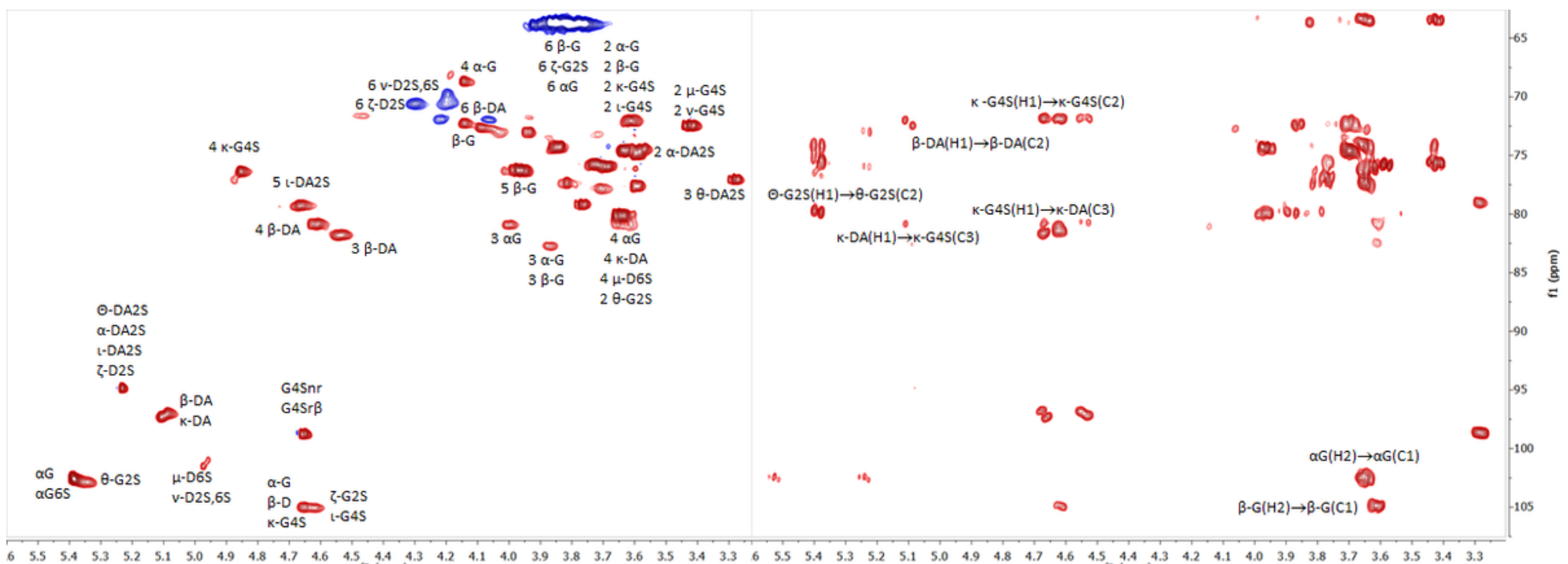

Figure 7

HSQC (left) and HMBC (right) spectra of GSW
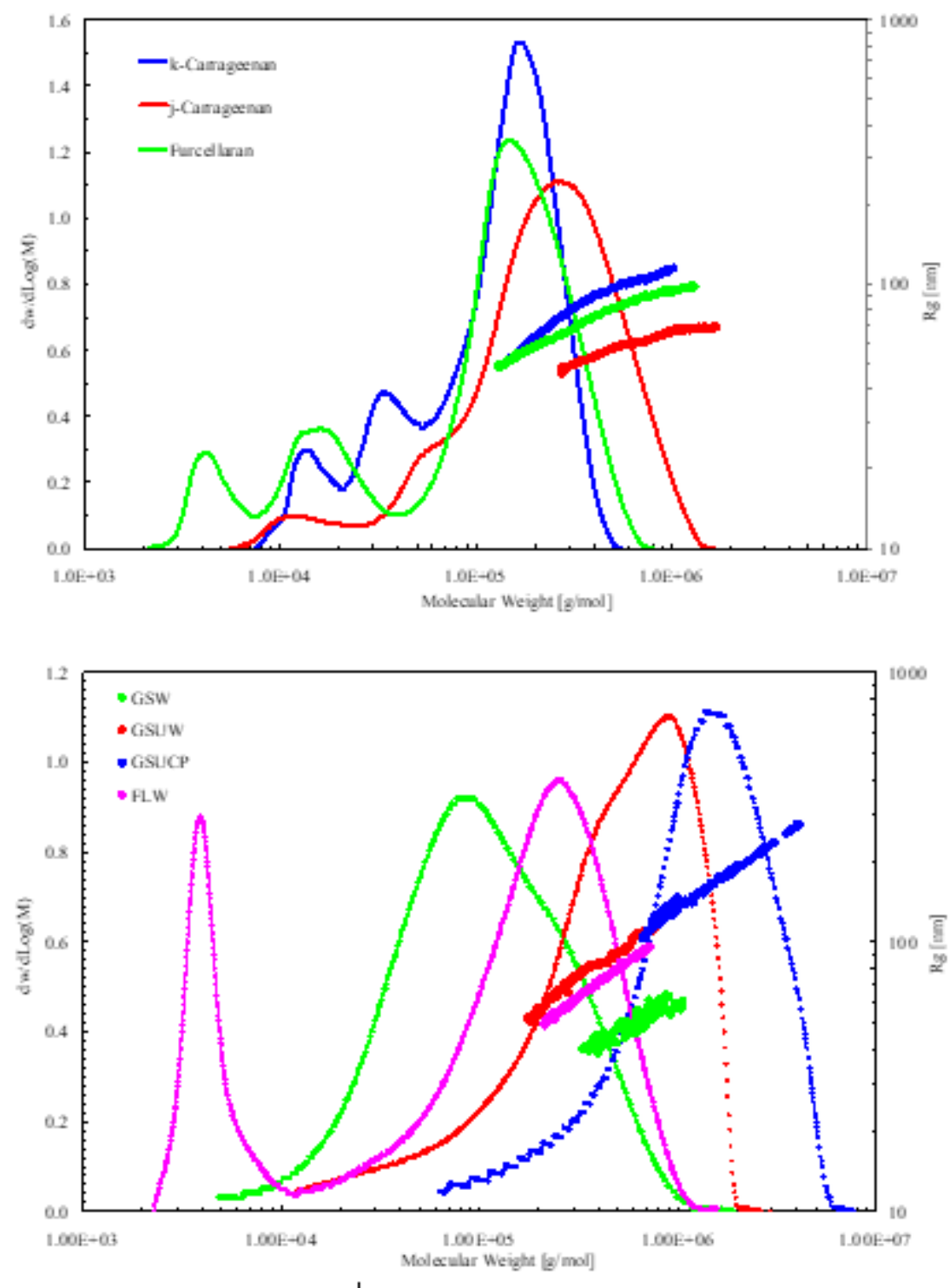
Figure 8

Comparison of MWD and $\mathrm{Rg}=\mu(\mathrm{M})$ conformation plot. Top panel from top to bottom of the main peaks: $\mathrm{K}$-carrageenan (blue), furcellaran (green) and l-carrageenan (red); for the bottom panel from right: GSUCP (blue), GSUW (red), FLW (violet) and GSW (green) MWD of K-, l-carrageenan and furcellaran (Fig. 8, upper panel) shows three peaks (i.e. three components) with molecular weight ranging from very high to relatively low. On the contrary, MWD of GSUCP, GSUW, FLW, and GSW (Fig. 8, bottom panel), with exception of FLW sample shows a single main peak with molecular weight ranging from very high to high. FLW sample show also a minor low molecular weight peak $(\mathrm{Mp}=3.8 \mathrm{~kg} / \mathrm{mol})$. Summary of the SECMALS results (Mp and Amount) for $\mathrm{K}$-, l-carrageenan and furcellaran is in Table 1.

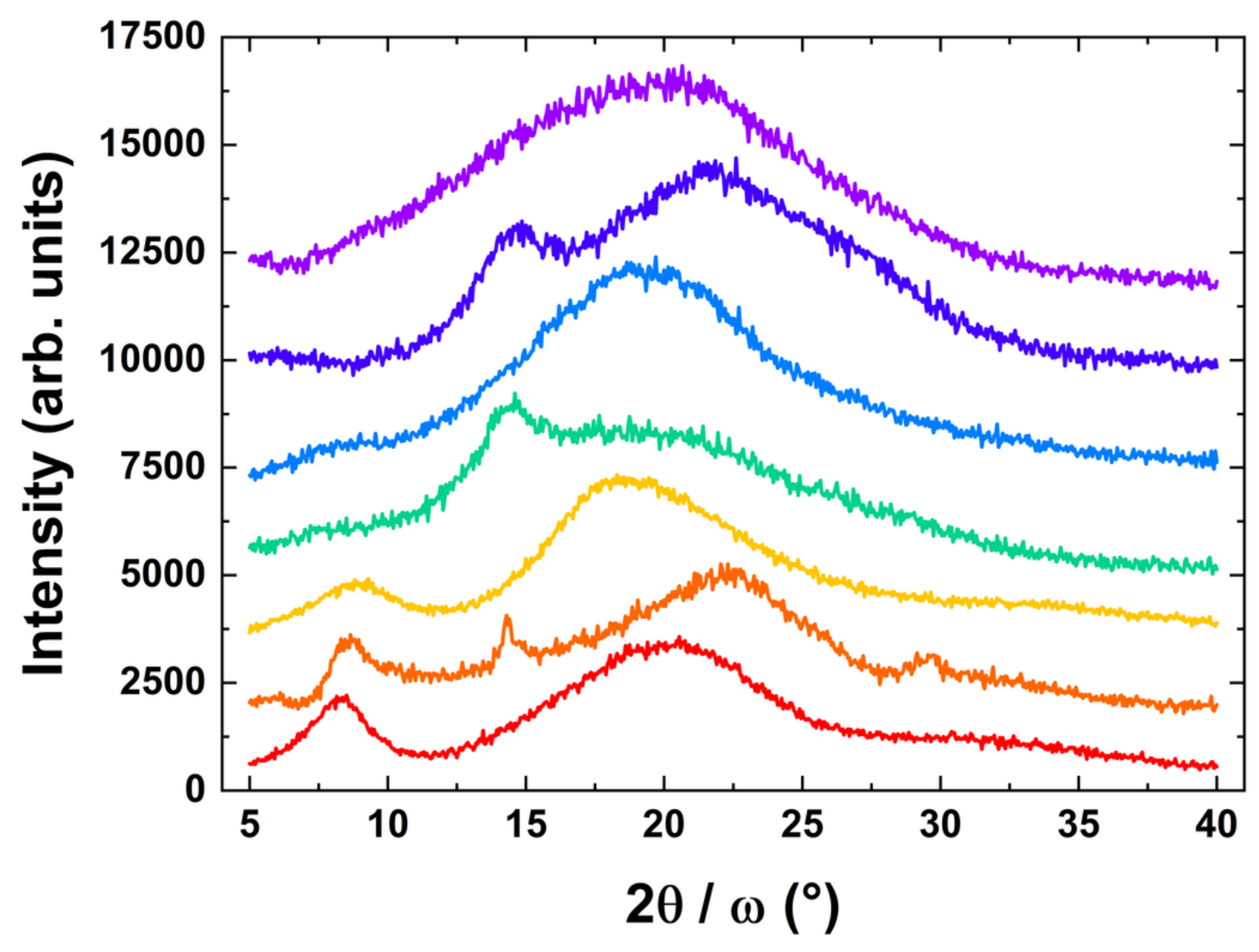

Figure 9

XRD profiles of GSUCP, FLW, GSW, GSUW, Furcellaran, l- and k-carrageenan films (top to bottom) 

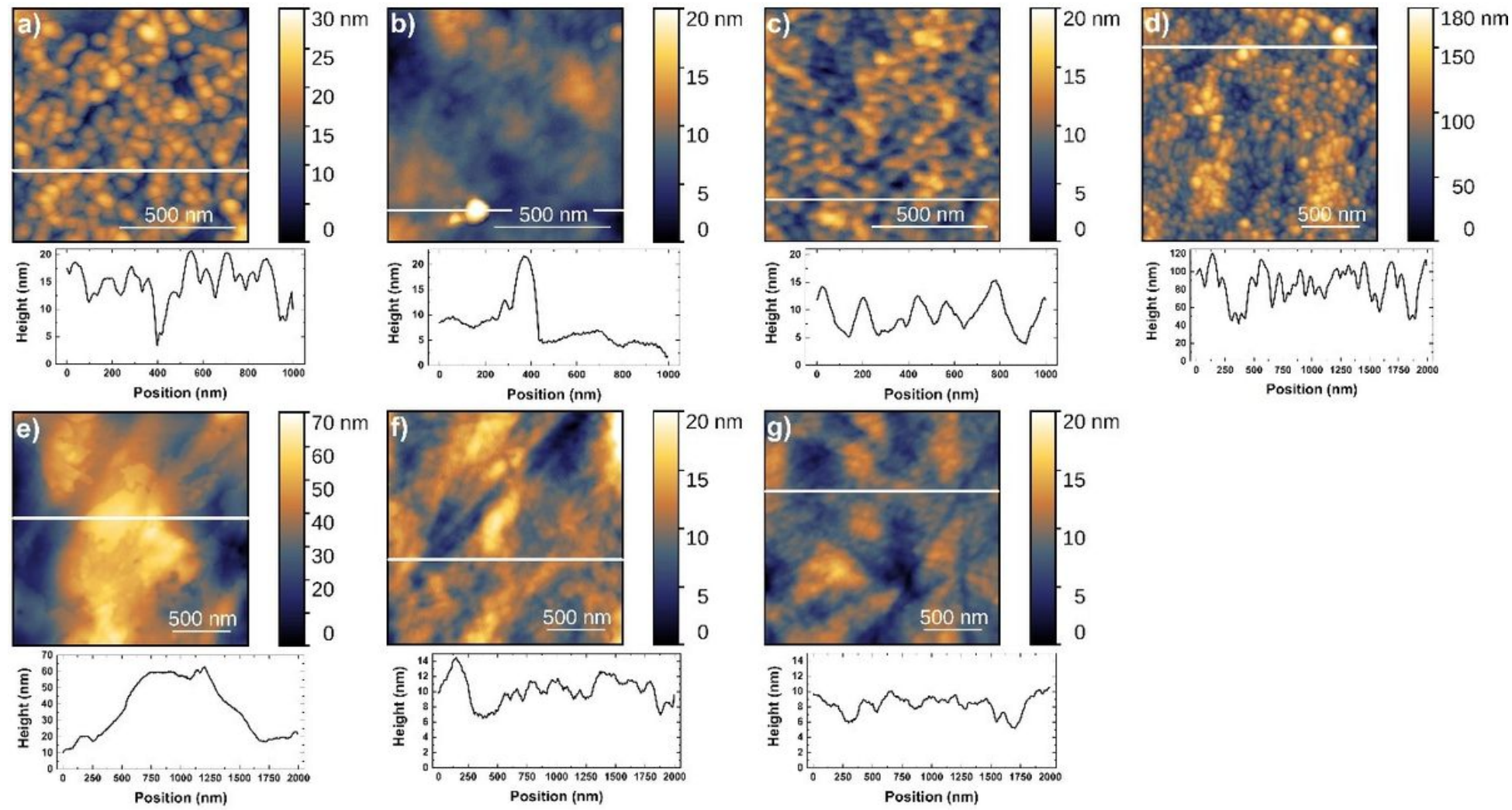

Figure 10

Representative $1 \mu \mathrm{m} \times 1 \mu \mathrm{m}$ and $2 \mu \mathrm{m} \times 2 \mu \mathrm{m}$ topography scans with corresponding line profiles extracted along designated horizontal white lines of l-carrageenan (a); GSW (b); K-carrageenan (c); furcellaran (d); GSUW (e); GSUCP (f); and FLW (g)

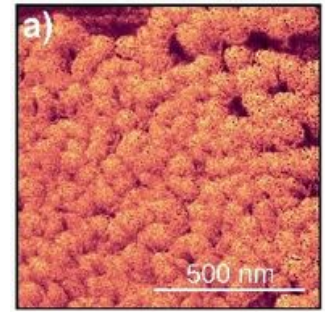

e)

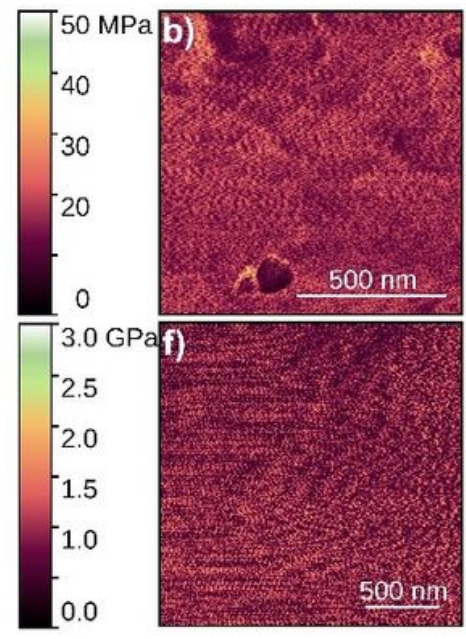

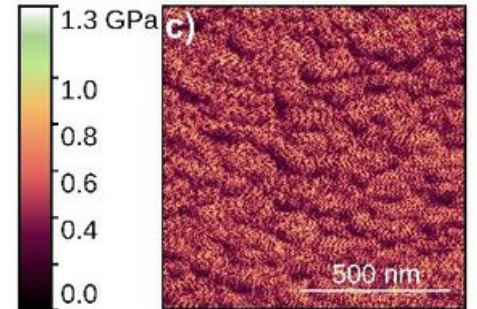

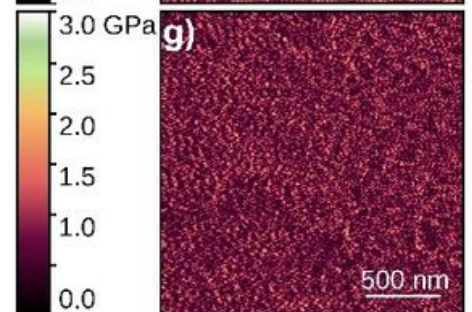

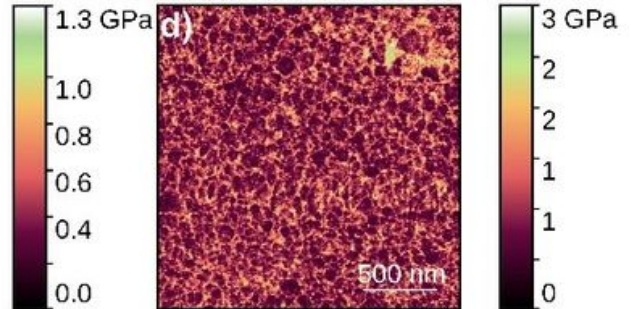

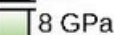

\section{Figure 11}

PF-QNM reduced modulus maps of t-carrageenan (a); GSW (b); k-carrageenan (c); furcellaran (d); GSUW (e); GSUCP (f); and FLW (g) 

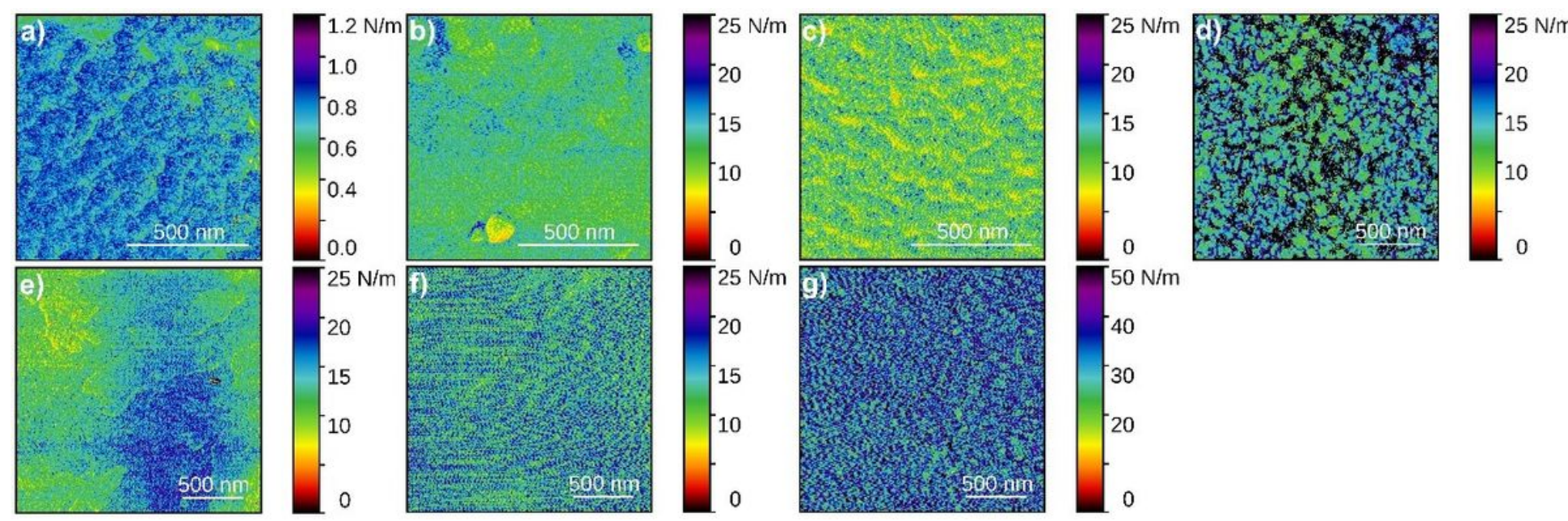

Figure 12

PF-QNM stiffness maps of t-carrageenan (a); GSW (b); k-carrageenan (c); furcellaran (d); GSUW (e); $\operatorname{GSUCP}(\mathrm{f}) ; \mathrm{FLW}(\mathrm{g})$
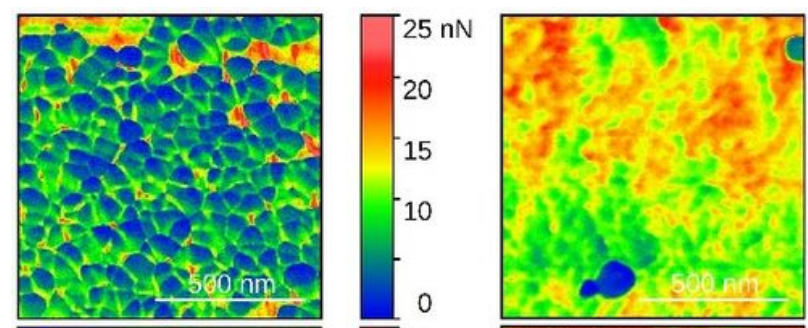

e)
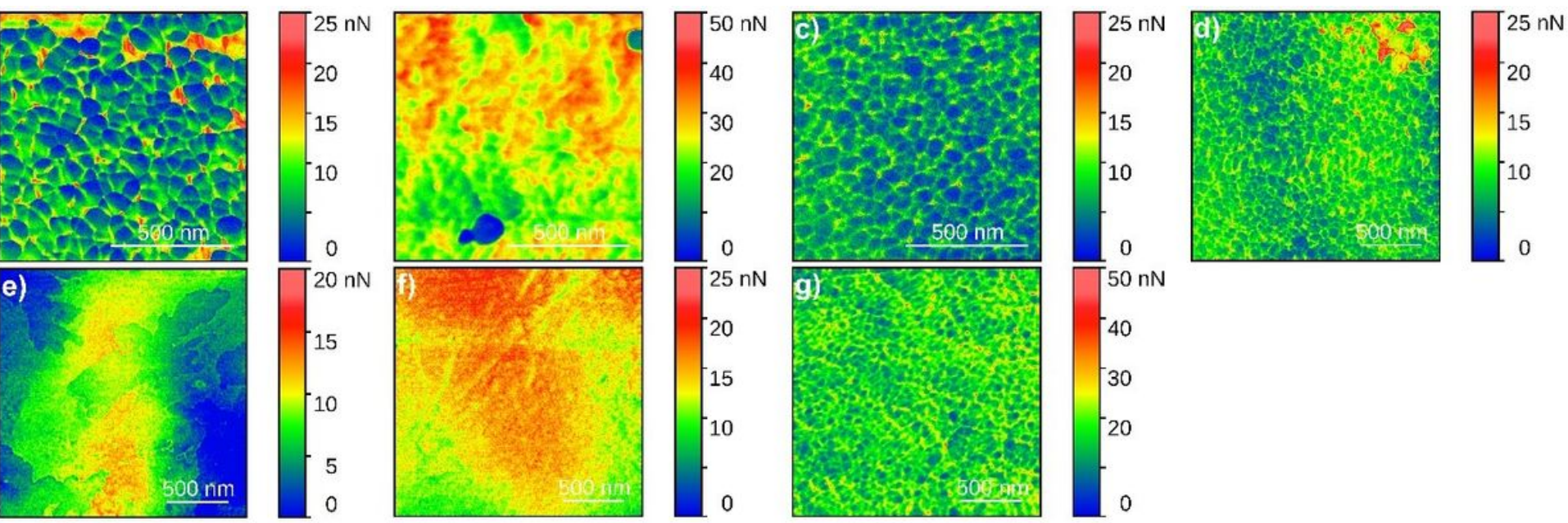

Figure 13

PF-QNM adhesion maps of t-carrageenan (a); GSW (b); k-carrageenan (c); furcellaran (d); GSUW (e); GSUCP (f); FLW (g) 

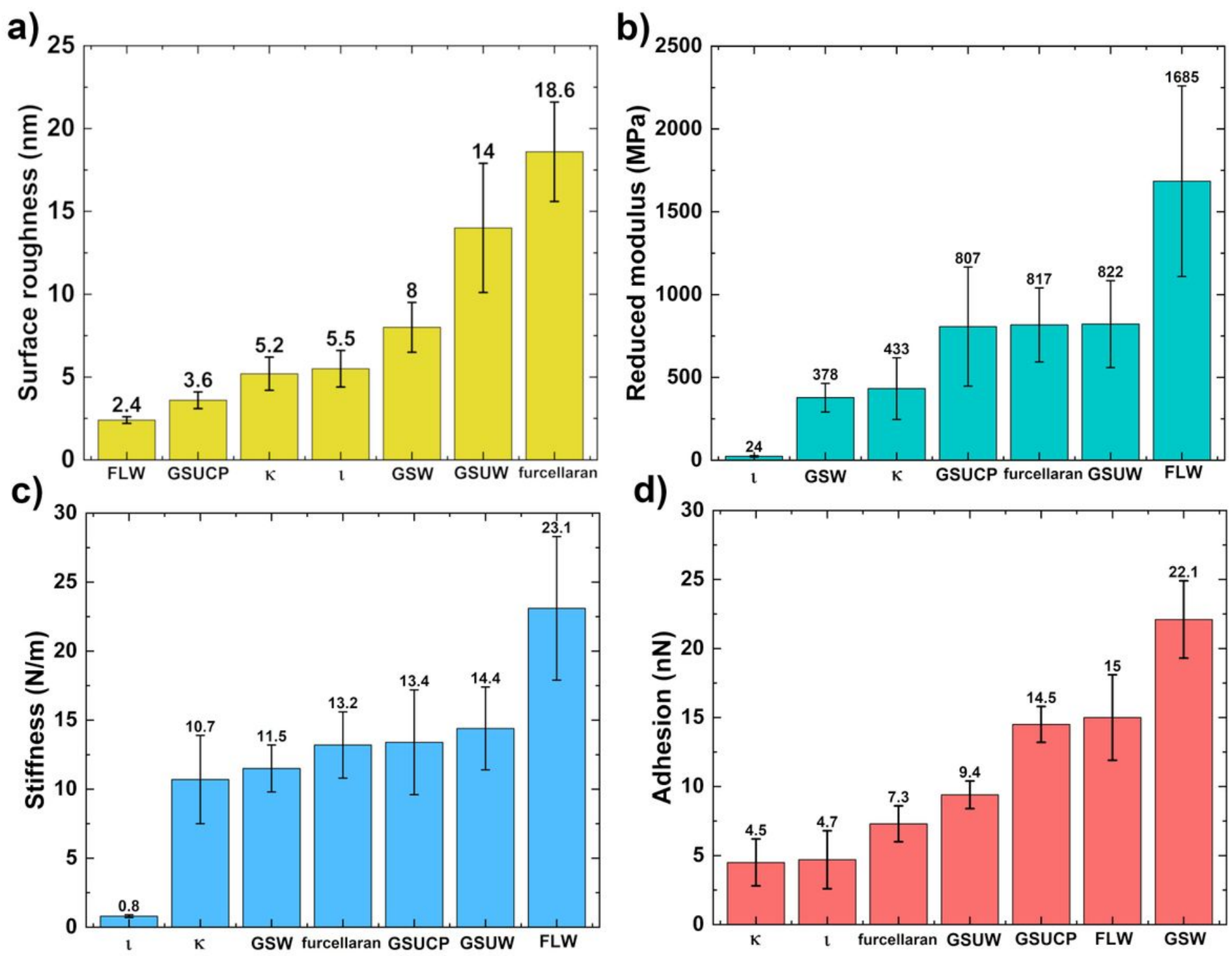

Figure 14

AFM and PF-QNM determined values of RMS surface roughness (a); reduced modulus (b); stiffness (c); and adhesion (d) of GSW, t-carrageenan, K-carrageenan, furcellaran, GSUW, FLW, and GSUCP allpolysaccharide composite films

\section{Supplementary Files}

This is a list of supplementary files associated with this preprint. Click to download.

- SupportingInfoFLGScelluloseManus.docx 